\title{
LOS PROBLEMAS DE LAS TEORÍAS HOLISTAS DEL DERECHO
}

\author{
Juan Manuel Pérez Bermejo \\ Universidad de Salamanca
}

RESUMEN. Este ensayo sitúa y caracteriza las teorías holistas del Derecho, y trata de dar respuesta a las críticas más comúnmente dirigidas contra ellas. Las teorías holistas se presentan como teorías de la justificación según las cuales la conclusión de un razonamiento se justifica en virtud de su adecuación a la totalidad del sistema en el que aspire a integrarse. El ensayo defiende estas teorías como las únicas capaces de responder al problema lógico de la justificación, y observa que sus exigencias principales son también demandas habituales de la práctica jurídica. De entre los problemas a los que estas teorías deben hacer frente, el ensayo selecciona cuatro: a) La inclusión de antinomias y contradicciones frustra la capacidad del sistema para generar justificaciones. b) La idea de actuación unitaria supone que cada cambio en la composición del sistema implica un cambio de sistema. c) Los discursos jurídicos habituales no apelan al sistema en su conjunto, sino a un pequeño número de normas. d) La justificación holista tiene sentido únicamente si presumimos el sistema omnicomprensivo de todos nuestros conocimientos.

Palabras clave: holismo, razonamiento jurídico, sistema jurídico, coherencia, antinomia, subsistema jurídico, identidad del sistema, cambio de sistema, unidad del conocimiento.

ABSTRACT. This paper defines the holistic theories of law and tries to answer the most common objections raised against them. Holistic theories are outlined as justification-theories for which the conclusion of any reasoning is justified according to its adequacy to the whole system of reference. This paper defends holistic theories as the only ones able to overcome the logical problems of justification, and sustains that their main requirements are also common demands of legal practice. I have chosen to address four among the many criticisms raised against them: a) Legal systems normally include many antinomies and contradictions, so they cannot be source of justification. $b$ ) If legal systems act like a whole, any change of any rule represents a change of legal system. c) Normal legal reasonings do not appeal to the whole legal system, but to a small number of its rules. d) Logically, holism only works under a strong assumption of unity in our whole knowledge.

Keywords: holism, legal reasoning, legal system, coherence, antinomy, legal subsystem, system's identity, change of system, unity of knowledge. 


\section{LAS TEORÍAS HOLISTAS DEL DERECHO: UNA PRESENTACIÓN BREVE}

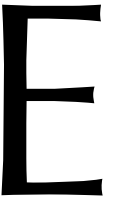

1 título de este ensayo puede despertar en el lector dos interrogantes severos acerca de su sentido y su objeto. El primero versa sobre la existencia misma de las teorías a las que alude, las teorías holistas del Derecho. Éstas no parecen contar en nuestra literatura con una personalidad reconocida y diferenciada del resto: un manual introductorio de teoría del lenguaje o del conocimiento suele dedicar un capítulo importante a las concepciones holistas del lenguaje o de la justificación; no ocurre así en los manuales de teoría jurídica, donde el holismo carece de papel protagonista, e incluso de papel secundario. Es posible, sin embargo, que el lector reconozca la existencia de algunas teorías del Derecho que, por atribución propia o de terceros, se suelen calificar de holistas. Pero, en ese caso, un segundo interrogante preguntará cuál es el mensaje o el significado concreto del holismo con el que estas teorías se reconocen. En efecto, no creo que exista en nuestra disciplina una convicción firme sobre las tesis básicas que incorpora el holismo, ni siquiera sobre los problemas concretos a los que trata de dar respuesta: en la teoría del lenguaje, sabemos que las teorías holistas responden al problema de por qué atribuimos a nuestras frases un determinado contenido o significado; en la teoría del conocimiento, sabemos que se enfrentan al problema de la justificación de creencias, es decir, resuelven cuándo una de nuestras creencias merece el rango de conocimiento «justificado» $\mathrm{o}$ «garantizado», y puede ingresar en nuestro sistema de creencias admitidas; en teoría del Derecho, sin embargo, parece más aventurado concretar a qué problema responden y en qué ámbito se aplican.

Pese a la importancia de estos interrogantes, creo que su respuesta puede formularse de una forma breve. Respondiendo al segundo de ellos, clasificaré las teorías holistas del Derecho como, principalmente, teorías de la justificación o del razonamiento jurídico, porque aspiran a distinguir las proposiciones que se siguen correctamente de un razonamiento jurídico de aquellas otras que podemos juzgar como incorrectas. En este contexto, las teorías holistas se definen por ofrecernos un test de justificación muy particular, y que coincide con el que manejan las teorías holistas de la justificación que hallamos en la teoría del conocimiento: la proposición que evaluemos (una creencia, una norma...) se justifica atendiendo al criterio de su adecuación al sistema total de proposiciones en el que aspire a integrarse. Para este grupo de teorías, la respuesta al problema de la justificación se halla siempre en el sistema. En rigor, la justificación es siempre una función del sistema en su conjunto, no de una proposición o un grupo de proposiciones, y si decimos que una creencia o una norma están justificadas es únicamente porque pertenecen a un sistema que suponemos justificado. Comprobamos así que, para las teorías holistas, la respuesta al problema de la justificación se halla en la teoría del sistema ${ }^{1}$. Por último, el primer interrogante puede zanjarse provisionalmen-

\footnotetext{
1 «El test [de justificación] que aplicamos es el del sistema» (BRADLEY, 1914: 202). BONJOUR remite el problema general de los patrones de justificación de la epistemología a la «estructura de un sistema» (BONJOUR, 1985: 16). «Operamos, en efecto, con la ecuación «justificado» = «sistematizado» (RESCHER, 1974: 705). Como veremos, la mayoría de los autores holistas identifican «justificación» y «coherencia» de todo el sistema. Por esa razón, la fórmula que he empleado es fiel a otras fórmulas holistas como: «Una creencia está justificada si pertenece a un conjunto coherente de creencias» (HAACK, 1993: 34). Ver también QUINE, 1963: 40-41; HARMAN, 1973: 160; BRINK, 1989: 103-104. En el ámbito de la teoría del lenguaje, la respuesta al problema del conteni-
} 
te advirtiendo que, si la tesis básica del holismo es la que acabamos de formular, las teorías que la defienden no son en absoluto desconocidas en la teoría jurídica. Más aún, el punto de vista antes presentado sobre el problema de la justificación puede reconocerse incluso como arraigado en la mentalidad jurídica.

Puede que la respuesta a estos interrogantes sea fácil de formular; sin embargo, resulta difícil de explicar, y más todavía en un apunte breve. Ésa es la razón por la que, en este primer epígrafe, presentaré las tesis básicas del holismo recurriendo a fórmulas muy genéricas, y sin detenerme en muchos de los problemas envueltos en su discurso. En un primer paso, acudiré al dominio más común de estas teorías, que es el de la teoría del conocimiento, para extraer sus tesis fundamentales (1.1); en un segundo paso, valoraré si estas tesis pueden ser aplicadas correctamente al ámbito del sistema jurídico, o si exigen matizaciones que deban subrayarse (1.2). Posteriormente, en el epígrafe 2 expondré los problemas intrínsecos a cualquier concepción holista de la justificación o del sistema, y la extensión de éstos a las concepciones holistas del sistema jurídico. Finalmente, en el epígrafe 3 trataré de ofrecer alguna salida a estas dificultades.

1.1. Teorías holistas de la justificación y del sistema. Una explicación desde la teoría del conocimiento. Es frecuente establecer una identificación entre teorías holistas y teorías coherentistas, de modo que una teoría holista sería aquella que propone como fórmula de justificación la coherencia del sistema. De ser esto cierto, la explicación de las teorías holistas del sistema podría satisfacerse cómodamente remitiéndonos a la literatura disponible sobre el valor de la coherencia, y contraponiendo estas teorías a las llamadas «fundacionalistas». Sin embargo, la realidad es más compleja, y no admite una identificación simple: es cierto que la inmensa mayoría de las teorías coherentistas son holistas ${ }^{2}$, pero no faltan holismos fundacionalistas o, al menos, no comprometidos con el coherentismo ${ }^{3}$. La explicación que nos aguarda no puede resolverse mediante la conocida distinción entre fundacionalismo y coherentismo $\mathrm{s}^{4}$.

Una teoría holista de la justificación se opone a una teoría «relacional», y, especialmente, a una teoría «local». Llamo una teoría relacional y local a aquella que justifica de modo suficiente una proposición en virtud de la serie limitada de inferencias que puedan establecerse entre dicha proposición y un sub-conjunto de proposiciones del sistema de referencia (sea éste el de las proposiciones de la Física, la Geografía, la Política...). Por ejemplo, el elemento $e$ queda justificado suficientemente dentro del sistema de referencia $S$ en virtud de las inferencias lógicas que sostiene con el subconjunto de tres elementos de $S\{a, b, c\}$. La justificación es «relacional» porque la fuente de la justificación es una relación comparativa entre proposiciones o elementos del sistema, relación que se traduce en una serie de inferencias lógicas. La justificación es «local» porque se circunscribe a un sub-conjunto del sistema. Es posible que este sub-conjunto mantenga relaciones de cohesión con el resto de elementos del sistema; en ese caso, podrá presumirse que el elemento $e$ sostendrá, aunque con menos fuerza, relaciones con

do proposicional de las creencias es, para los holistas, el sistema total de creencias del sujeto. DAVIDSON, 1984: $168,200$.

${ }^{2}$ La excepción más notable es la teoría coherentista de K. LEHRER. Para este autor, la coherencia o la justificación «no es un rasgo global del sistema», y «no depende de rasgos globales del sistema» (LEHRER, 1997: 31).

${ }^{3}$ La idea es subrayada en PeAcock, 1999: 233; MARMOR, 1991: 405.

${ }^{4}$ Sobre esta distinción, ver, por ejemplo, SOSA, 1980; BRINK, 1989. 
el resto de elementos del sistema. Pero también es posible que dicha cohesión sea muy limitada, y que la mayor parte de los elementos del sistema resulten irrelevantes desde el punto de vista del elemento $e$, en cuyo caso las únicas inferencias significativas son las establecidas entre el sub-conjunto y el nuevo elemento. En cualquier caso, el factor decisivo de justificación reside en la fuerza de estas inferencias, una fuerza que proviene de la relevancia local y el ajuste lógico entre el nuevo elemento y el área del sistema delimitada por el sub-conjunto. El análisis no precisa adoptar un punto de vista integral u omnicomprensivo que abarque todo el sistema $S$.

Para los partidarios del modelo holista, la justificación no es suficiente si se limita a comparar una proposición y una serie de proposiciones del sistema, por amplia que ésta sea. En apariencia, explicamos muchas veces nuestras justificaciones mencionando no más que una serie muy limitada de inferencias lógicas con una serie muy limitada de elementos, y contextualizamos la justificación de un elemento o proposición dentro de un área muy localizada de cada ciencia o conocimiento, allí donde la proposición justificada nos parece especialmente relevante. Sin embargo, esta explicación se conforma con la estructura superficial del razonamiento. La justificación no se explica adecuadamente si no incluimos, por ejemplo, las razones que explican la admisión de un tipo de inferencias lógicas y no de otras, o las razones que explican la especial relevancia lógica de la proposición dentro de un área del sistema, o las que explican la autonomía relativa de la que pueda disfrutar dicha área. Cualquiera de estos problemas incorpora razones subyacentes de gran calado que normalmente no se expresan, pero que intervienen activamente a lo largo de todo el proceso, y que han de buscarse recorriendo todo lo largo y ancho del sistema. La presuposición -algunos dirían el a priori ${ }^{5}-$ de cualquier justificación es una presuposición del todo, del conjunto integral S. Sin el recurso a este punto de vista integral, el proceso de justificación resultaría incompleto o inconcluso. La idea capital de quienes sostienen una posición holista es que todo el sistema participa integral y unitariamente en cada empresa de justificación.

En la justificación holista, la fuente de justificación es el sistema completo, y ésta es otorgada por el sistema a cada proposición. Si el elemento $e$ resulta justificado no es en virtud de la fuerza que exhiba en alguna de sus conexiones lógicas, sino porque el sistema $S$ se supone justificado, y porque $e$ pertenece al mismo. Es cierto que, en un primer momento, lo que comprobamos es que $e$ mantiene una serie de conexiones estrechas con algunos elementos del sistema. En general, debe admitirse que la justificación del sistema se nutre de una serie de inferencias y de relaciones lógicas entre sus elementos. Sin embargo, no es un determinado tipo o cantidad de inferencias, ni tampoco unos determinados elementos del sistema quienes otorgan el título de justificación, y ello porque son el orden o la estructura del sistema quienes han validado o admitido previamente dichas relaciones lógicas y, con ello, quienes han permitido la incorporación de dichos elementos al sistema ${ }^{6}$. La justificación del sistema es condición de posibilidad para la justificación de cualquier proposición individual.

En el razonamiento holista, la justificación exige considerar cuatro pasos. Continuando con nuestro ejemplo, la proposición o el elemento $e$ están justificados dentro del sistema $S$ si:

\footnotetext{
5 SPOHN, 1999: 166.

${ }^{6}$ Sin la justificación holista o sistémica no hay justificación relacional posible (OLSSON, 1999: 123).
} 
a) En un primer momento, constatamos que $e$ sostiene una red de conexiones lógicas con el resto de elementos del sistema $S$, y que esta vinculación es más importante en fuerza y en número que la que mantienen otros elementos rivales o alternativos al elemento $e$.

b) El elemento o la proposición $e$ es una contribución positiva a la justificación del sistema $S$. El sistema $S$ cobra un mayor sentido incorporando $e$, y sus posibilidades de justificación resultan reforzadas.

c) El sistema $S$, incluido $e$, es un sistema justificado.

d) El elemento $e$ está justificado en virtud de su pertenencia a $\mathrm{S}^{7}$.

En suma, la justificación no es relacional porque no es función de una serie de comparaciones, sino que es una propiedad del sistema que éste transmite a sus elementos. Tampoco es una justificación local: si la justificación de un elemento depende de la justificación del sistema al que pertenece, es el todo el que actúa en cada proceso de justificación. El todo se despliega de forma redundante en cada justificación, y todos los elementos del sistema contribuyen a la justificación de todos sus miembros ${ }^{8}$. Lo que se reclama como justificación local esconde siempre una justificación global ${ }^{9}$.

\subsection{El holismo en la teoría del Derecho. Creo que existen dos razones en favor de} un enfoque holista del sistema jurídico.

La primera es una razón lógica, extraída de la teoría de la justificación, y que, aun siendo de carácter general, considero también válida para el razonamiento jurídico. El argumento más fuerte en favor del holismo es la imposibilidad de resolver de otro modo el problema lógico de la justificación ${ }^{10}$. Una teoría de la justificación de carácter relacional o local suele resolver el problema de la justificación de $A$ en virtud de su relación lógica con otro elemento que podemos llamar $B$. Ante la pregunta por la justificación de $B$, la teoría aduce la relación de $B$ con $C$, y la de $C$ con $D$, y la de $D$ con $E$, etc. Si el proceso se describe de este modo, la teoría tradicional está abocada a un conocido trilema: puede seguir estableciendo inferencias ad infinitum, con lo que no terminaría nunca de justificar nada; puede sancionar que hay un elemento final $Z$ que ostenta la condición de dogma indemostrable, lo que supone renunciar a la empresa misma de justificar; puede retroceder y sentenciar que $Z$ se justifica de nuevo en $Y$, y éste en $X$,

\footnotetext{
${ }^{7}$ Es aproximadamente la secuencia formulada en Bonjour, 1985: 92. Como he dicho, la mayoría de las versiones holistas son coherentistas. En estos casos, el enunciado $b$ ) resulta menos ambiguo: la fórmula «el sistema $S$ cobra un mayor sentido incorporando $e$ » quiere decir «el sistema $S$ es más coherente incorporando $e$ ».

8 «Nuestras afirmaciones sobre el mundo externo se enfrentan al tribunal de la experiencia no individualmente, sino sólo como un todo incorporado» (QuINE, 1963: 40-41). «La ciencia física es un sistema que debe ser tomado como un todo... Si algo va mal, si alguna anomalía es sentida en el funcionamiento de todo el sistema, el físico tendrá que escrutar qué órgano necesita ser sustituido o modificado sin la posibilidad de aislar este órgano o de examinarlo por separado, sino considerando su efecto en todo el sistema» (DUHEM, 1906: 240-241).

${ }^{9}$ BRINK, 1989: 123; BONJOUR, 1985: 152.

${ }^{10}$ Existen otras razones. Una de las más repetidas es la necesidad de contar con el holismo para resolver paradojas como la de la lotería. Supongamos una lotería que otorga un solo premio y vende muchísimos números. Las posibilidades matemáticas de obtener el premio son astronómicamente remotas. Quien piense comprar el número 1 , si es racional, se abstendrá de hacerlo, porque las posibilidades de que el número 1 salga premiado exceden el umbral de esperanza racional, y abonan el juicio «el número 1 no va a ser elegido». Lo mismo sucederá con quien piense comprar el 2, el 3, 4... El resultado es que, para la lógica, ningún número va a resultar elegido, lo que es falso. La paradoja se resuelve «si consideramos que la regla probabilística de aceptación es relevante no en cada hipótesis individual, sino en el sistema completo de lo que aceptamos» (HARMAN, 1973: 119; OLSSON, 2002: 251).
} 
así hasta llegar de nuevo a $A$, que se remite a $Z$... con lo cual incurrimos en un círculo vicioso $^{11}$. Un razonamiento relacional y local no logra esquivar el trilema: suponer que $e$ queda justificado por sus inferencias lógicas con $a, b, \mathrm{y} c$ interrumpe de nuevo el razonamiento en algún punto en el que no sabemos dar cuenta de las razones en favor de $a, b \circ c^{12}$. En el fondo, el problema de esta estrategia consiste en interpretar la justificación como una propiedad que se transfiere o que viaja de unas piezas a otras del sistema; desde esta comprensión, las justificaciones resisten lo que resista el eslabón más débil de la cadena ${ }^{13}$. En su lugar, para las teorías holistas la justificación debe ser remitida a la totalidad del sistema, y ganar el refuerzo de todos los elementos del sistema, los más débiles y los más fuertes. Y, si ponemos como requisito de cualquier justificación el sentido o el significado completo de todo nuestro sistema de conocimientos, resulta ya vano aducir alguno de los lados del trilema: ocurre, simplemente, que la justificación de $e$ reúne todas las posibilidades de justificación, porque todo el sistema está comprometido en su defensa; y ocurre que, sin la justificación de $e$, la comprensión de todo el sistema está cuestionada.

Ahora bien, conviene advertir de una condición severa que ha de cumplirse para que el anterior argumento funcione: para que podamos concluir que el sistema está justificado, la totalidad del sistema ha de estar en orden, y ha de construirse de modo autosuficiente desde el punto de vista de la justificación. La percepción de cualquier inconsistencia, laguna o anomalía en nuestro sistema afecta a toda justificación posible, y ha de suponer la revisión del todo. El contacto con el mundo y la resolución de nuevos problemas cuestionarán frecuentemente el orden y la consistencia del sistema. El sistema está, por ello, permanentemente abierto al exterior, y dispuesto a renovar y reforzar su composición interna y sus posibilidades de justificación.

La segunda razón en favor del holismo en Derecho es ya propiamente jurídica. Si nos preguntamos cuál de las teorías alternativas de la justificación reconstruye de mejor modo la práctica de razonar o de argumentar en Derecho, creo que la alternativa holista es la que da cuenta más precisamente de su sentido y de sus presupuestos básicos. De hecho, el criterio holista está hondamente arraigado en la práctica jurisdiccional. En ella es evidente que la equidad o el trato igual de los mismos casos constituye una exigencia básica. Esta exigencia implica que la solución impuesta por el juez a un caso no puede ser contradicha en otro lugar del orden jurídico respecto a un caso idéntico o dotado de similitudes relevantes con el anterior. Eso significa que una decisión justificada presupone un juicio de equilibrio o de consistencia relativo a todo el sistema jurídico. Por eso los jueces imponen deberes y obligaciones en nombre de su comunidad y de su Derecho entendido éste como un todo

${ }^{11}$ La formulación del «trilema de Münchhausen» se debe, como es sabido, a H. ALBERT, que lo aprovecha para su crítica al deductivismo. Véase ALBERT, 1968: capítulo 1, sección 2.

${ }_{12}$ A la pregunta de por qué interrumpimos la justificación en $a, b$ o $c$, o por qué estos elementos resultan justificados, las teorías no holistas suelen apelar al carácter de justificación última de algunos de estos elementos; y, ante la pregunta de qué es lo que atribuye a alguno de estos elementos el título de justificación última, el razonamiento sólo podría aducir como argumento el carácter auto-justificado de los mismos, o bien señalar que poseen un especial estatuto lógico o epistémico que les exime del problema de la justificación. Tanto en uno como en otro argumento se incurre en el segundo de los lados del trilema, porque se interrumpe dogmáticamente la empresa de la justificación, haciéndola sospechosa de decisionismo. Ver POLLOCK, 1997: 103.

13 VIOLA, 1987: 389. 
unitario, integral, solidario, y que habla normativamente «con una sola voz» ${ }^{14}$. Cada razonamiento jurídico se construye así desde el trasfondo del sistema completo, y ello aun cuando, en la sentencia, se mencionen tan sólo una o unas pocas reglas. Cuando un juez español resuelve un caso, no aplica una determinada regla, sino el «Derecho español» en su totalidad, o, lo que es lo mismo, el sistema jurídico en su conjunto.

Por estas razones, hoy son numerosas las teorías del Derecho que incorporan un enfoque holista de la justificación. Sin poder respaldarlo mediante un censo exhaustivo, creo que el balance tendría que hablar hoy de un relativo auge ${ }^{15}$. Sin duda, este auge está asociado al de las teorías holistas más representativas, es decir, las teorías coherentistas $^{16}$. En cualquier caso, a los efectos del presente artículo, presumo que el método holista es correcto en la teoría de la justificación y del sistema jurídico; nada se afirma o se postula en torno a la corrección del método en otras ciencias sociales ${ }^{17}$.

Definidas las teorías holistas, y acordada su corrección en nuestro ámbito, sólo nos resta formular los rasgos de la justificación y del sistema jurídico desde la perspectiva holista. El orden jurídico se configura como un todo que actúa unitaria y solidariamente en cada una de sus aplicaciones. La justificación es siempre interpretada como una

${ }_{14}$ DwORKIN, 1986: 166. El veredicto «en nombre del Derecho español le condeno a $x$, si bien admito que puede haber razones suficientes en el Derecho español por las que esta sentencia es jurídicamente errónea e injusta» resulta paradójico.

15 Dejando a un lado precedentes menos explícitos, el holismo sistémico halla su primer gran valedor para el Derecho en SAVIGNY. Su punto de vista de que el sistema compone una «totalidad orgánica» o una «unidad inmanente» parece interpretar el holismo como una teoría ontológica sobre la realidad jurídica, y explicar la vinculación de las normas como una vinculación material o no reducible a inferencias lógicas (SAVIGNY, 1849: 32). Ello plantea diferencias notables con respecto al holismo contemporáneo, para el cual la integridad es meramente un principio de justificación, no un principio de constitución del sistema, y que suele tener una idea formal e inferencial de las relaciones entre normas. Las ideas de SAVIGNY sobre el sistema son, pese a todo, cambiantes y problemáticas. Ver, por ejemplo, HERNÁNDEZ GIL, 1979: 273 y ss. Dejando a salvo la tradición de la dogmática alemana del XIX, creo que en la teoría del Derecho de posguerra son pocos quienes, hasta la irrupción del pensamiento de DwORKIN, hacen expreso el holismo en teoría jurídica. Lo hallamos en un trabajo pionero de SARTORIUS que sigue las teorías de la investigación de A. SCHEFFLER. Ver SARTORIOUS, 1968: 135. De modo más expreso y desarrollado, lo encontramos ya en HOFFMASTER, 1980. La idea ha sido popularizada con éxito por DwORKIN, y de ella da buena cuenta el emblema definidor de su teoría, Derecho como «integridad». «La interpretación jurídica es inherentemente holista», y ello es así «incluso cuando el aparente blanco de la interpretación es una sentencia singular» (DWORKIN, 1986: 80). Después, MACCORMICK lo ha defendido de forma contundente: «Si alguien rechazara enfocar el Derecho de forma holista como un sistema coherente, cada decisión, presumiblemente, tendría que ser considerada como tomada en sus propios méritos en relación con alguna interpretación atractiva de las normas relevantes para el caso concreto. De modo radical, el Derecho se aproximaría entonces a una inspiración poética relativa al caso» (MACCORMICK, 1993: 24). En las últimas dos décadas, los estudios sobre la integridad o la coherencia del sistema se han hecho habituales. No es extraño que algunos epistemólogos hayan propuesto el caso de la práctica judicial como paradigma de razonamiento holista. Ver HARMAN, 1989: 134-135.

16 No es necesario que mostremos el éxito del holismo coherentista exhibiendo una lista de autores. Basta con remitirnos a RAZ, para quien «la coherencia está de moda entre los juristas» (RAZ, 1994: 277), o a EDMUNSSON, para quien «hoy somos todos coherentistas» (EDMUNDSON, 1994: 1). Sin que sea ahora posible precisar qué añade la coherencia al holismo, sí es conveniente advertir que buena parte de los debates que se reconstruyen en este ensayo se han generado en la literatura coherentista.

17 Por eso no son de nuestra incumbencia definiciones del método holista pensadas para la sociología o la ciencia política, y que ponen el acento en el carácter supraindividual de las unidades de estudio (BUNGE, 1999: 363). Que, en estos dominios, el método derive en consecuencias políticas totalitarias tampoco es relevante en nuestro discurso. El sistema jurídico unifica normas, no individuos; y dicha unificación, en autores como DwORKIN, está vinculada a la mejor defensa de los derechos individuales. 
propiedad del sistema jurídico. Las conclusiones de un razonamiento jurídico se justifican por su pertenencia al sistema jurídico.

Deberá admitirse en este esbozo que no sería adecuado remitirnos mecánicamente al esquema de justificación tomado de la epistemología, y pensado mayormente para esquemas de creencias y proposiciones fácticas. Creo, sin embargo, que esta cautela es compatible con la defensa de su utilidad para la teoría jurídica en forma de guía aproximada o de recurso analógico. Puede así sostenerse que, en el razonamiento jurídico, una conclusión $c 1$ está justificada si: a) Mantiene una serie de relaciones lógicas con otros elementos del sistema jurídico $S$, y estas relaciones son más estrechas en fuerza y número que las que mantienen sus rivales $c 2, c 3 \ldots b)$ El sistema $S$ cobra un mayor sentido incorporando $c 1$ que incorporando sus alternativas rivales. $c$ ) El sistema $S$, incluido $c 1$, está justificado. d) Por consiguiente, $c 1$ está justificada por su pertenencia a $S^{18}$.

Finalmente, una teoría holista de la justificación implica una cierta caracterización del sistema jurídico. En concreto, una teoría holista cree que el sistema jurídico es una totalidad auto-suficiente en materia de justificación. Para sus defensores, ésta es la única alternativa capaz de superar el trilema antes mencionado, que deja a las teorías no holistas atrapadas en el regreso al infinito, el círculo vicioso o la interrupción dogmática. Ahora bien, si el sistema jurídico es una totalidad auto-suficiente, entonces el sistema contiene una respuesta correcta y única para cualquier caso que se le presente. Las teorías holistas, sobre todo las teorías coherentistas de nuevo cuño, no dudan en suscribir esta tesis. Puede que, en un primer momento, el sistema jurídico no ofrezca una respuesta explícita al caso difícil dentro de su formulación inicial. Pero, ante ese problema, el jurista debe profundizar en las raíces últimas de la justificación del sistema, y tratar de identificar elementos que, tal vez, habían pasado inadvertidos; de ese modo, el jurista revisa el sistema, corrige antiguos errores, y, de ese modo, el sistema potencia sus posibilidades de justificación. El modelo holista de sistema es el de un sistema móvil y que tiende a a la comprehensividad —es decir, la búsqueda de la auto-suficiencia o la compleción - a través de la complejidad —es decir, el reforzamiento progresivo de sus posibilidades de justificación. Este punto de vista es, precisamente, una de sus mayores fuentes de dificultad; mencionaremos ésta y otras en el siguiente epígrafe.

\section{DIFICULTADES Y OBJECIONES}

De entre las muchas críticas que la anterior descripción ha recibido, he seleccionado aquellas que parecen más relevantes en el ámbito jurídico. Algunas de ellas provienen más bien de la teoría del conocimiento, pero son también comprometedoras para una teoría holista del Derecho.

${ }^{18}$ Omito considerar el problema de cuál es el tipo de holismo aplicable en Derecho. Por ejemplo, algunos autores distinguen entre un holismo «invariabilista» y otro «adicionista». El invariabilista comparte el punto de vista de G. E. MoOre, según el cual una vez que adjudicamos un valor a todo el conjunto resultará que el valor de cada miembro no es otro que el valor que expresa el todo. Si el sistema $S$ se compone de $\{a, b, c\}$ y le adjudicamos el valor $V$, el valor de $a$ será siempre $V$ en cualquier contexto. Este punto de vista es rechazado por J. DANCY, que rechaza el invariabilismo e interpreta el holismo de un modo puramente «adicionista»: el valor de un conjunto no es más que la suma de los valores de sus miembros. Una discusión lúcida sobre estos puntos de vista se halla en BROWN, 2007. 
2.1. La primera crítica niega la posibilidad de que el sistema jurídico pueda ser interpretado como un todo unitario. La razón es sencilla: el sistema jurídico puede albergar inconsistencias y antinomias numerosas y flagrantes, lo que puede ejemplificarse en la vigencia de normas inválidas o incluso de normas inconstitucionales dentro del siste$\mathrm{ma}^{19}$. Una teoría holista presume que la justificación es una propiedad de todo el sistema; y, más aún, presume que un razonamiento holista integra la totalidad de los elementos del sistema y de sus relaciones de apoyo mutuo. Si esto es cierto, cualquier razonamiento jurídico interpretado de un modo holista es incorrecto, y ello porque este razonamiento presumirá incorporado dentro del mismo el inevitable número de inconsistencias, antinomias y leyes inválidas que están en vigor dentro del sistema; y, si uno o varios pasos del razonamiento son contradictorios, la conclusión será por fuerza incorrecta ${ }^{20}$. Sin embargo, todos admitimos que, aun constatando la existencia de antinomias dentro del sistema, los juristas elaboran a diario razonamientos correctos. Y, si aprobamos estos razonamientos, es porque asumimos que éstos nunca o casi nunca involucran la totalidad del sistema. Lejos de ello, los juristas se conforman con justificaciones suficientes que provienen de las relaciones o de las inferencias lógicas que una conclusión mantiene con algunos elementos del sistema jurídico; gracias a ello el jurista ejerce un control sobre sus premisas, y tiene garantía de que éstas no incluyen contradicciones. Así las cosas, no tiene sentido proclamar que un razonamiento jurídico es correcto si sus conclusiones pueden integrarse dentro del sistema: la justificación no puede ser una operación que comprometa al sistema en su conjunto, sino el producto de una serie limitada de inferencias ${ }^{21}$.

2.2. Un segundo problema de las teorías holistas es el de hacer difícilmente compatible la identidad continuada en el tiempo del sistema jurídico y su carácter dinámico.

Para quienes lo señalan, este problema se sigue lógicamente de la descripción del sistema como una red de elementos que mantienen relaciones de apoyo mutuo. En las descripciones más habituales del modelo holista, como son las coherentistas, es frecuente declarar que todos los elementos del sistema contribuyen positivamente a la justificación de todos los demás, de modo que cada elemento resulta ser una pieza esencial dentro del engranaje de justificaciones del sistema. Este carácter implica que cada elemento resulta ser una condición necesaria para el sostenimiento de todos las demás. Si esta descripción es correcta, entonces será cierto afirmar que cualquier cambio en la conformación del sistema jurídico (una sola alta, una baja o una sustitución) representará una transformación de toda su estructura de justificaciones, y, con ello, alumbrará un sistema completamente nuevo ${ }^{22}$.

19 «Es realmente una ingenuidad — bastante difundida en la teoría del Derecho [y añade en nota: "donde es completamente común definir la validez como pertenencia al ordenamiento”] — pensar que sólo las normas válidas pertenecen al ordenamiento» (GUASTINI, 2004: 254). Por otra parte, aun cuando pudiera exhibirse un sistema jurídico supuestamente libre de antinomias, en este caso la crítica podría limitarse a recordar el segundo teorema de GÖDEL, según el cual «ningún sistema puede probar su propia consistencia».

${ }^{20}$ Para Foley, el holismo sólo tiene dos salidas, y las dos inaceptables: negar que sean posibles las antinomias por algún tipo de infalibilismo, o caer en el escepticismo. Y todo, en sus palabras, porque no puede apartarse del proverbio «una sola manzana pudre todo el cesto» (FOLEY, 1979: 257)

${ }^{21}$ Esta crítica ha conducido a algunos coherentistas a apartar el holismo de sus teorías, porque «hay sistemas inconsistentes que justifican muchas creencias» (LEHRER, 1999: 253). Ver también TERSMAN, 1993 : 36.

${ }^{22}$ Existe una forma de interpretar este fenómeno que es trivialmente verdadera: si incorporamos una nueva creencia o nos desprendemos de otra, nuestro conjunto de creencias es distinto. Esta interpretación, sin embargo, no asume que estas altas o bajas comprometan inferencialmente el resto de creencias. La tesis que aho- 
Aplicada esta tesis al sistema jurídico, la consecuencia es que cada acto de promulgación o cada acto de derogación, cada nueva sentencia o cada nuevo contrato extingue el sistema jurídico hasta entonces conocido, e instaura uno nuevo. Un sistema jurídico es, con ello, un elenco de reglas que podemos elaborar desde un punto de vista sincrónico. Ahora bien, la identidad de este sistema durará lo que tarde alguno de los operadores jurídicos en realizar un cambio en dicho elenco, por mínimo que éste sea. Desde el punto de vista diacrónico, el sistema será extraordinariamente inestable.

En la teoría del conocimiento, esta crítica ha sido formulada de este modo: las teorías holistas son inaceptables porque, de ser ciertas, llevarían asociada una «tesis de la inestabilidad» de los sistemas o «tesis del cambio total» ${ }^{23}$, según la cual el cambio en un elemento de un sistema es un cambio de sistema. En este dominio, es fácil demostrar que la crítica resulta devastadora: decir que cada vez que cambio de opinión en una sola de mis creencias poseo un sistema de conocimientos o una visión del mundo distinta de la que tenía antes no tiene sentido ${ }^{24}$. En la teoría del Derecho, sin embargo, la tesis del cambio total es acogida sin complejos por ALCHOURRÓn y BULYGIN, y por los seguidores de su modelo de sistema ${ }^{25}$. A estos autores no les pasa inadvertido que, bajo tal inestabilidad, el concepto de sistema no se ajusta a nuestro uso ordinario: en general, no juzgamos que una simple modificación o reforma de las leyes positivas desencadena un cambio de todo el sistema jurídico. Por esta razón, estos autores distinguen entre el sistema jurídico, entendido como conjunto sincrónico de normas, y el «orden jurídico», que es «una secuencia dinámica de conjuntos (sincrónicos) de normas» ${ }^{26}$ : cualquier cambio de normas ocasiona un sistema nuevo, pero el orden jurídico permanece estable si el cambio se ha producido conforme a los criterios de cambio reconocidos por dicho orden. Mi presunción es, sin embargo, que los problemas denunciados por la teoría del conocimiento para los sistemas de creencias son igualmente aplicables a los sistemas de normas: parece contrario al sentido común que una sola sustitución dentro del sistema ocasione un cambio completo de sistema. Afectado por la tesis de la inestabilidad, la vida de un sistema jurídico es tan efímera que éste se convierte en un objeto de investigación irrelevante. Más importante aún, admitida la tesis del cambio total, el sistema se convierte en una realidad estática, cristalizada en torno a un conjunto inmodificable de preceptos. Pero, así descrito, el sistema resulta ser algo muy distinto a un sistema jurídico. Como sabemos, un sistema jurídico es un objeto construido ex profeso para experimentar el cambio y la movilidad; por esta razón, ligar la identidad del sistema a la perspectiva estática parece enfrentado con el elemento dinámico inseparable de cualquier sistema jurídico.

2.3. La dificultad más conocida de los modelos holistas proviene del empeño por comprender el sistema como una totalidad auto-justificada. Como sabemos, el modelo

ra manejamos es, sin embargo, que un solo cambio modifica la estructura de justificaciones sobre la que descansan todos los elementos del sistema, lo que compromete a todas las creencias sin excepción. De ese modo, una nueva creencia es una transformación del esquema de creencias que sostenía la composición del sistema, razón por la cual el sistema es distinto una vez operado el cambio. Véase WiLliams, 1991: 276.

${ }^{23}$ Tomo la fórmula de PAgIN, 2005: 13.

${ }^{24}$ Fodor y Lepore, 1991: 11-22. También Putnam, 1986.

25 Alchourrón y Bulygin, 1971: 138; GuASTINI, 1996: 349-351; Moreso y NAVARRO, 1993. La distinción de ALCHOURRÓN y BULYGIN entre «sistema» y «orden jurídico» también es explícita en RAZ, aunque éste denomina a ambos conceptos «sistema momentáneo» y «sistema jurídico». RAZ, 1970: 34-35.

${ }^{26}$ GUASTINI, 2004: 268. Sobre la relación entre «orden jurídico» y los sistemas jurídicos consecutivos, me parece muy instructivo RODRíGUEZ, 2002: 121 y ss. 
holista rehuye los problemas tradicionales de la justificación atribuyendo esta propiedad a un todo con sentido. Una conclusión justificada procede de un razonamiento que integra la totalidad de los elementos del sistema y la totalidad de las relaciones que éstos mantienen entre sí.

Si éste es su mensaje básico, el holismo ha sido acusado en la teoría del conocimiento de describir erróneamente el proceso de justificación. Como prueba se aducen algunos casos de incorporación justificada de creencias en los cuales, con certeza, no presumimos la unidad o la totalidad del sistema de conocimientos. Como ilustra el ejemplo de DummetT, desde el holismo nunca podríamos explicar el proceso mediante el cual un niño aprende un idioma: el niño no puede aprobar un término o una relación sintáctica por su mayor o menor coherencia con el todo, y ello por la sencilla razón de que el bagaje idiomático con el que cuenta es un porcentaje mínimo de ese todo ${ }^{27}$. Para muchos de estos críticos, si las teorías holistas no logran explicar estos casos es porque dependen de una presunción irrealista, como es la participación de todos los elementos del sistema en cada una de sus aplicaciones: por muy superiores que sean nuestros conocimientos a los del niño, nunca contamos con una representación de la totalidad del sistema de conocimientos, aunque sea el de una rama o disciplina concreta. En cualquier caso, nuestras justificaciones son parciales o locales, porque éstas no abarcan todo el sistema de referencia, ni siquiera una mayoría de éste; lejos de ello, las justificaciones se localizan dentro de un área del sistema relacionada con el problema concreto, y se limitan a reunir las premisas suficientes para respaldar la conclusión.

Esta acusación, tan tópica en la teoría del conocimiento, parece igualmente aplicable al Derecho. En la argumentación jurídica, los razonamientos más comunes invocan un número reducido de normas pertenecientes a un área muy localizada del sistema, y no parece creíble que, en realidad, lo que el jurista moviliza en cada caso es la totalidad del orden jurídico de su comunidad. El holismo afirmaría que un razonamiento sobre, por ejemplo, derecho urbanístico presume necesariamente todo nuestro saber acumulado sobre Derecho civil, laboral, constitucional, etc. Por el contrario, las sentencias judiciales, las querellas o las demandas habituales se limitan a invocar las normas relevantes para el caso, y alcanzan soluciones satisfactorias mediante un aparato argumentativo breve.

Sin duda, los juristas mencionan sus argumentos normativos de un modo lógicamente organizado, de modo que su tarea está presidida por una intención lógico-sistemática. Sin embargo, los juristas no reconstruyen sistemáticamente la totalidad de las normas de su comunidad, sino que se conforman con sistematizaciones parciales ${ }^{28}$. Muchas veces, estas sistematizaciones parciales han sido reiteradas en el tiempo o consa-

27 DummetT, 1991: 221.

28 AlChOURRÓn y BulYgin, 1971: 122. RATTI observa que podemos denominar «sistema» un número muy escaso de normas relacionadas entre sí por el jurista. Con ello, lo que trata de subrayar es que las tareas de sistematización no reconstruyen todo «el ordenamiento jurídico» de una comunidad, sino, más simplemente, el número de normas suficiente para justificar una determinada conclusión jurídica. Como puede verse, mi ensayo no distingue entre sistema interno y externo, es decir, entre el orden inmanente al Derecho y el orden construido por el jurista. RATTI sí distingue cuidadosamente entre ambos conceptos, y, por ello, entiende que los conjuntos normativos que son en general suficientes para justificar una conclusión jurídica pueden ser de dos clases: puede tratarse de un «sub-sistema», que es un conjunto diferenciable mediante la sistemática legislativa, o de un «micro-sistema», que es un conjunto diferenciable, pero siguiendo una técnica sistematizadora ajena a la legislativa. RATTI, capítulo 1, 14-16. 
gradas por la práctica, y han consolidado conjuntos o sub-sistemas de normas que responden a criterios de unidad distintos, y que están presididos por leyes propias. A veces, estos sub-sistemas son de relativa envergadura, porque coinciden con áreas o departamentos muy generales y claramente diferenciados entre sí2 ${ }^{29}$. Sin embargo, a veces bastan sistematizaciones menores construidas en torno a una institución, una categoría o un concepto doctrinal.

Las teorías holistas del sistema no niegan que estas divisiones tradicionales cuentan a veces decisivamente en la justificación de una sentencia. Sin embargo, reiteran que el sistema jurídico se moviliza integralmente en cada empresa de justificación, lo que incluye aquellos casos en los que creemos habernos servido del modo de razonar más distintivo de una determinada rama del sistema, y también aquéllos en los que pensamos haber movilizado un área muy reducida o insignificante del sistema jurídico. El jurista parece así siempre responsable de una reinterpretación completa de todo el cuadro de reglas, principios y valores jurídicamente operativos de su comunidad. Ahora bien, apelando a un mínimo realismo, los críticos observan que el jurista no es casi nunca tan ambicioso; $y$, de perseguir dicha ambición, es muy dudoso que pudiese alcanzarla. Por esa razón, tanto el jurista como su comunidad quedan plenamente satisfechos con justificaciones muy locales

2.4. La última crítica es una derivación de la anterior, porque se limita a extraer radicalmente las consecuencias a las que nos conduce la presunción del todo. Debemos recordar de nuevo que la justificación holista está condicionada por la comprensión del sistema como una totalidad auto-suficiente. Ahora bien, para que esta totalidad resuelva los problemas con los que le interroga el contacto con el mundo es preciso entenderla como una totalidad móvil y flexible, capaz de integrar dentro del sistema elementos anteriormente inadvertidos o considerados como exteriores al mismo. La práctica enfrentará al sistema con problemas de su competencia para los cuales no dispondrá de una respuesta clara. En estos casos, la posibilidad de que el sistema aporte una justificación es que recupere su sentido completo, y, para ello, necesitará incorporar nuevos elementos o identificar otros hasta entonces no formulados, lo que supondrá una revisión o una reformulación del sistema hasta entonces conocido. En la imagen de la hermenéutica, la justificación no describe exactamente un círculo, sino una espiral que se proyecta hacia fuera en busca de una continua reconstrucción de sentido ${ }^{30}$. En la imagen de la teoría coherentista del sistema, éste se caracteriza por su disposición al aprendizaje mediante un incremento progresivo de su complejidad ${ }^{31}$. En cualquier caso, esta proyección hacia fuera y esta continua reformulación de su contenido parece no tener límite: tanto la propia búsqueda de justificación como los intereses pragmáticos del sistema empujan a éste a una irradiación ilimitada que tiende a traspasar su tradicional marco de referencia. Dicho de otro modo, el reforzamiento del sistema no respeta las fronteras canónicas establecidas entre las distintas ramas del saber o del conocimiento, y mueve a cualquier sistema a incorporar elementos de otros sistemas diferentes.

${ }^{29}$ En un ejemplo común, podría contrastarse un derecho de daños teñido de valoraciones morales con un Derecho penal en el que rigen estrictamente los principios de legalidad y no retroactividad. BAUM LEVENBOOK, 1984: 367, 371 .

${ }^{30}$ Ver, por ejemplo, OsBORNe, 1991.

${ }^{31} \mathrm{La}$ cualidad del aprendizaje y de la complejidad progresiva es subrayada en las teorías del sistema que adoptan el modelo en red. Ver, por ejemplo, BAR-YAR, 2003. 
Por este motivo, muchos partidarios del modelo holista confiesan que la justificación no es una propiedad que pueda limitarse a un particular sistema de conocimientos, sino que sólo es imputable a lo que podríamos llamar el «sistema de sistemas», es decir, el sistema omnicomprensivo de todos nuestros saberes y creencias. La justificación holista presume así la tesis de la unidad del conocimiento. Si la base de la justificación reside en el apoyo mutuo de todas nuestras creencias, nuestro saber total sólo puede comprenderse como una red integrada, y no como una lista de ramas o de ciencias disgregadas. El sistema de referencia del que hemos hablado hasta ahora sería en realidad el único sistema posible, que es el sistema completo de nuestras creencias. Cualquier empresa de justificación supone la aplicación de todo el conocimiento humano entendido como unidad ordenada y sistematizada ${ }^{32}$. Sin aludir a corriente doctrinal alguna, denominaré esta derivación del holismo como «la tesis de la unidad del conocimiento».

Aunque parezca lo contrario, el problema antes descrito debería resultarnos familiar en la teoría del Derecho de los últimos años, en la cual la incorporación de la moral al Derecho preside una vez más la agenda de problemas. Para DwORKIN y sus seguidores, la respuesta a un problema jurídico puede venir determinada por la respuesta a un problema moral, respuesta que supone un enriquecimiento del sistema jurídico y una reformulación de sus elementos. Ahora bien, la respuesta al problema moral puede también depender de la respuesta a un problema epistémico, como puede ser el problema de la verdad de los valores, o incluso de un problema ontológico, como puede ser la realidad de los valores morales o la existencia dentro del sistema de una respuesta correcta para cada problema. Para DwORKIN, muchas veces resulta explícito que la investigación no puede constreñirse dentro de los límites de un discurso, y es preciso adentrarse dentro de otros discursos y disciplinas, y tratar de que todos ellos queden en orden cuando concluya nuestra investigación. Lo que este fenómeno revela es que la justificación, en Derecho o en cualquier discurso, persigue «la búsqueda de una armonía amplia... entre todas nuestras opiniones». Cuando DwORKIN prescribe el principio de integridad como principio supremo de justificación, además de pronunciarse por un modelo holista de sistema, prescribe un principio que debe aplicarse a toda la «estructura intelectual» del individuo, a la totalidad de sus conocimientos y saberes, lo que incluye, como mínimo, todos sus principios y reglas prácticas, sus valores estéticos y sus creencias sobre la realidad ${ }^{33}$.

Este imperialismo sistémico supondría, además, agravar las dificultades 1, 2 y 3. Si, en palabras de QUINE, «cada unidad de significación empírica es la totalidad de la cien-

${ }^{32}$ La tesis queda reflejada en el título del gran proyecto de NEURATH: Encyclopedia of Unified Science (19381970). Es clásica la visión de QUINE: toda la ciencia es un campo de fuerza (QuINE, 1951: 43). También es común en el coherentismo clásico (JOACHIM, 1969: 107) y en el moderno (SPOHN, 1950: 159; BONJOUR, 1985: 97; YOUNG, 1995). MOULINES habla incluso de un holismo super-quineano, un holismo que no toma como unidad el sistema de creencias, sino el de la cultura de un período histórico, lo que englobaría doctrinas metafísicas, credos religiosos y actitudes éticas. Los ejemplos de esta actitud son escasos, pero puede mencionarse a HEGEL o SPENGLER (MOULINES, 1986: 318).

${ }^{33}$ DwORKIN, 1996: 19. Sección «Epistemological Hierarchy». La idea está ya presente en 1991: «Queremos que todas nuestras convicciones formen un sistema, y no una mera colección; confiamos en que nuestras convicciones políticas estén nutridas, y no meramente toleradas, por nuestras creencias económicas, psicológicas y metafísicas» (DwORKIN, 1991: 198). La tesis ha hallado un defensor esforzado en M. MoORE, quien ha criticado «la tesis de la autonomía del discurso» como forma de relativismo profundo (MOORE, 1989: 953 y ss.) y de provincianismo (parrochialism) ideológico (MoORE, 1992: 2432). 
cia» ${ }^{34}$, la implicación recíproca entre proposiciones acentuará los problemas antes formulados. En el marco de la dificultad 1, una teoría holista llevada hasta sus últimas consecuencias implicaría, por ejemplo, que una inconsistencia en nuestros conocimientos de historia del arte haría imposible justificar una tesis de física nuclear ${ }^{35}$. Lo mismo sucede con la tesis de la inestabilidad radical: cualquier cambio en cualquier rama del conocimiento supondría el paso de un sistema total a otro, un cambio en nuestra visión del mundo y en nuestra concepción de la realidad ${ }^{36}$. Los problemas involucrados en la dificultad 3 también se acrecientan, porque no parece realista suponer que nuestras justificaciones movilizan nuestro sistema completo de creencias. En primer lugar, la tesis parece poco verosímil, porque ningún individuo parece capaz de representarse el sistema completo de conocimientos y creencias. Pero, en segundo lugar, lo cierto es que nuestro conocimiento y nuestras tareas de justificación se desarrollan en contextos radicalmente diferenciados, y juzgamos erróneo trasplantar indebidamente las leyes de un contexto a otro. Las reglas y los criterios de valoración difieren en un experimento de psicología y en otro de zoología; más claramente, juzgamos sin sentido que alguien reniegue de la estética de un cuadro aduciendo que representa un unicornio, y que los unicornios no existen ${ }^{37}$. Por eso ocurre muchas veces que, cuando creemos estar ensanchando nuestra perspectiva local, en realidad no nos estamos situando en el punto de vista del todo, sino en una perspectiva local distinta: por ejemplo, cuando ampliamos la perspectiva moral integrando la perspectiva económica, lo que ocurre muchas veces no es que nuestra perspectiva local (moral) se haga más rica y comprensiva, sino, más simplemente, que hemos cambiado de problema y de contexto, de modo que ya no hablamos de moral, sino de economía ${ }^{38}$. La perspectiva local es autosuficiente, y no necesita presumir la perspectiva global o la totalidad de nuestro saber.

Finalmente, la ambición de convertir todo nuestro saber en un sistema unitario y cohesionado podría, paradójicamente, debilitar la posición del conocimiento y de la ciencia ante los desafíos escépticos. En efecto, la pregunta por la justificación última de, por ejemplo, nuestro sistema jurídico podría, tal vez, hallar respuesta en la moral, y la pregunta por la justificación de la moral en alguna teoría de la verdad o de la objetividad; sin embargo, si todo nuestro saber se integra en un todo unitario, en ese caso estaremos en más dificultades para responder a quien nos interrogue por el sentido del todo, y a quien nos advierta que podemos estar en un error total. Reducido el saber a un todo unitario, ya no podemos ofrecer ninguna prueba externa que garantice su corrección, y la pregunta del escéptico acerca del sentido de nuestro saber queda necesariamente sin respuesta ${ }^{39}$.

\section{UN CAMINO POSIBLE PARA LAS TEORÍAS HOLISTAS}

En lo que sigue, presentaré un esquema de respuestas a las anteriores críticas respetando el orden con el que fueron mostradas.

34 QUINE, 1951: 42.

35 Tomo el ejemplo de BOnJOuR, 2003: 45. Lo que los últimos escritos de Bonjour tienen de retractación respecto a sus tesis de los 80 es imputable, en gran medida, a su actual rechazo del holismo radical y de la tesis de la unidad del conocimiento.

36 Harman, 1973: 169; Williams, 1991: 275-276, 284.

37 Tomo el ejemplo de Stavropoulos, 1996: 181.

38 Ver, por ejemplo, Williams, 1991: 287-292.

39 Williams, 1999: 192-195. 
3.1. ¿Podemos atribuir al sistema la propiedad de la justificación aunque constatemos habitualmente la vigencia de inconsistencias y de antinomias entre sus elementos?

Una primera salida a esta dificultad sería adherirse a las numerosas propuestas que, desde la lógica, nos permiten extraer consecuencias válidas desde premisas inconsistentes: desde sus postulados, la tesis clásica ex falso quodlibet resulta ajena a la práctica científica, y habría que definir un lenguaje lógico alternativo y compatible con esta realidad. La defensa del holismo no precisa, sin embargo, de un compromiso decidido con lógicas heterodoxas ${ }^{40}$. Mi respuesta se limita a sugerir que una teoría del sistema ha de esforzarse por conciliar dos afirmaciones que son intuitivamente aceptables, pero de difícil conjunción: $a$ ) el hecho de que dos elementos del sistema sean inconsistentes no nos obliga a concluir que todos los demás son injustificados ${ }^{41}$; $b$ ) la consistencia del sistema es una condición inseparable de los procesos de justificación.

Simplificando el problema, creo que pueden señalarse dos razones por las cuales podría ser insensato negar la justificación de un determinado razonamiento por el hecho de que el sistema contiene inconsistencias.

La primera razón es que la consistencia lógica no es una condición exclusiva de justificación. Para que un sistema pueda justificar conclusiones y resolver los problemas de los que es competente no basta con afirmar que sus elementos no se contradicen; deben considerarse también otros valores. Ésta es una idea muy arraigada en las versiones holistas más representativas, las coherentistas, donde se subraya que la consistencia no es el único criterio de coherencia - y, por tanto, de justificación- que debe ser manejado, sino que existen otros que deben aplicarse simultáneamente al de consistencia, como pueden ser el grado de cohesión de los elementos del sistema, su unidad o su complejidad. Consideremos dos sistemas, $S 1$ y $S 2$. $S 1$ es un sistema altamente complejo y sofisticado; está dotado de una alta movilidad que lo convierte en un modelo flexible, apto para el aprendizaje y, por tanto, para resolver problemas imprevistos; pese a su complejidad, sus miembros están altamente cohesionados, lo que se traduce en una ausencia completa de elementos triviales o irrelevantes; por último, el sistema adolece de un número escaso de inconsistencias. $S 2$ es un sistema simple y poco flexible, posee además un número importante de elementos aislados y poco relevantes, pero es impecable desde el punto de vista de la consistencia, y carece de contradicciones. Para los coherentistas, cualquier científico juzgaría más fructífero $S 1$ que $S 2$, y cualquier jurista, del mismo modo, habría de juzgar más apto para la obtención de soluciones correctas un sistema como $S 1^{42}$. La segunda razón nos obliga a considerar cuál es el sentido de la consistencia en el sistema jurídico de acuerdo con el modelo holista. Consistencia significa la posibilidad de extraer una interpretación unitaria del sistema jurídico: exigir

${ }^{40}$ Me refiero, por ejemplo, a la lógica paraconsistente o a las lógicas de la relevancia. En el mismo sentido, ver THAGARD, 2004: 15 .

${ }^{41}$ «Alguien que cree que al menos una de sus creencias es falsa tiene un sistema de creencias inconsistente, pero seguramente es erróneo decretar que, entonces, ninguna de las creencias de su sistema está justificada» (GOLDMAN, 1989: 5).

${ }^{42}$ Son muchos quienes subrayan la exigencia sobre los sistemas de algo más que consistencia. Ver, por ejemplo, HARMAn, 1973: 124; HARMAN, 1989: 15; RESCHER, 1973: 204. En Derecho, se ha observado con frecuencia la admisión de contradicciones en las sentencias, siempre y cuando éstas no sean decisivas. En el ejemplo italiano, sólo puede casarse una sentencia por contradictoria si es imposible entender la ratio decidendi, lo que ha llevado a COSTANZO a hablar de una lógica paraconsistente en la Corte italiana (CostANZO, 1992: 26). 
consistencia es exigir que el sistema nos hable con una sola voz, y que contenga una respuesta correcta para cada problema jurídico planteado. Si éste es el sentido fundamental de la consistencia, hemos de concluir que la condición se halla satisfecha cada vez que el sistema sea capaz de proporcionarnos una respuesta clara para el caso particular por el que le interrogamos, y ello aun cuando un recorrido más amplio por las razones que incluye el sistema detecte alguna antinomia. Creo que al jurista le resultará posible percibir con claridad cuál es la respuesta que patrocina el sistema si la inconsistencia o las antinomias engastadas dentro del mismo se ajustan a las condiciones que formularé en el siguiente párrafo.

En efecto, es cierto que muchas veces alcanzamos justificaciones suficientes en el contexto de un sistema que adolece de antinomias. Ahora bien, la presencia de antinomias dentro del sistema delata la incorporación de errores y de anomalías suficientes para anular muchas de sus posibles conclusiones. Como vimos antes, el sistema merece un margen de confianza si podemos acreditar cuál es la voz con la que habla; pero el sistema no merece esta confianza si abunda en contradicciones, y, con ello, si nos resulta difícil reconstruir su juicio con demasiada frecuencia. Es muy posible que la consistencia no sea el único valor involucrado en los procesos de justificación; sin embargo, tampoco es aceptable minimizar o incluso negar su concurso: el sistema debe atesorar el mayor grado posible de consistencia, y las antinomias deben ser contempladas como errores que pueden y deben ser corregidos ${ }^{43}$. A las dos razones que pueden aducirse para hacer compatible la justificación y la presencia de algunas antinomias hemos de añadir una serie de condiciones necesarias para que sea posible lograr una justificación aceptable en un sistema que contiene antinomias: a) En general, las contradicciones o inconsistencias han de ser muy escasas en número, y las normas afectadas han de tener una irradiación relativamente reducida dentro del sistema. b) En cada caso particular, las normas inconsistentes han de participar en una medida muy escasa en la justificación de las conclusiones, y resultar ser, por tanto, de fuerza o de relevancia muy reducida. c) El sistema de referencia ha de ser lo suficientemente complejo como para disponer de recursos suficientes con los que resolver todas las antinomias detectadas.

Las condiciones $a$ ) y b) ilustran aquellas situaciones en las que resulta posible obtener claramente la respuesta patrocinada por el sistema en su conjunto al problema planteado a pesar de que el sistema contiene inconsistencias y antinomias. La tercera condición se traduce en una idea muy valiosa: la justificación en un sistema que contiene antinomias sólo es posible bajo la convicción de que un despliegue completo de las razones que contiene el sistema mostrará con claridad que éste se pronuncia por una

${ }^{43}$ Algunos teóricos de la coherencia, deseosos de poner de relieve que coherencia es algo más que mera consistencia lógica, no dudan en subrayar que la consistencia es incluso innecesaria para la coherencia (MACCORMICK, 1993: 266). Sin embargo, la consistencia es, conceptualmente, un ingrediente irrenunciable de la coherencia, y una exigencia insoslayable de cualquier sistema holista (BONJOUR, 1985: 95). Que, en la realidad, sea preferible un sistema muy complejo y levemente inconsistente a otro simple y consistente es una cuestión discutible y, desde luego, compatible con la afirmación de que el ideal es siempre que el sistema carezca por completo de inconsistencias. Como observa OLSSON, la consistencia es el criterio de coherencia que cuenta con mayor respaldo intuitivo, y el único sobre el que tienden a coincidir los teóricos de la coherencia (OLSSON, 1999: 281). «Los lógicos paraconsistentes toleran y a veces incluso elogian las inconsistencias, pero la mayoría prefiere resolverlas. Si HARRY nos dice $x$ en un caso y SALLY nos dice $-x$ en el mismo caso, tendemos a pensar que uno de los dos está equivocado... En lugar de transigir con las inconsistencias, el fin de los agentes, que se esfuerzan por alcanzar un estado mental equilibrado, es evitar las inconsistencias y restaurar la consistencia» (ROTT, 2001: 85). 
de las dos normas en disputa ${ }^{44}$. Las antinomias y las normas inválidas son errores que afectan negativamente a la vida del sistema, y que han de poder ser subsanados por el sistema mismo. Media una diferencia cualitativa importante entre un sistema en el que se cometen algunos errores, pero que liga su justificación a la posibilidad de subsanarlos, y otro dentro del cual se juzgue como inevitable que los jueces, en última instancia, tengan que dirimir conflictos insolubles entre soluciones jurídicas incompatibles ${ }^{45}$. En este segundo caso, creo que resulta imposible escapar a las implicaciones de la lógica ortodoxa, y sugerir que de un sistema de este tipo puede derivarse cualquier cosa. El primero, sin embargo, no es un modelo intolerablemente inconsistente aun cuando en él se constaten algunos errores. Estos errores podrán permanecer incrustados en el sistema durante un tiempo más o menos prolongado; ocurre, simplemente, que el proceso de detección de errores no es maquinal y automático, sino que está sujeto a la falibilidad del conocimiento humano. Sin embargo, el postulado holista de la unidad o de la integridad se respeta mientras se observen las condiciones anteriores, en especial la que estipula que todos los errores pueden y deben ser subsanados, porque el cuadro argumental completo del sistema se pronuncia claramente por una de las dos normas en disputa $^{46}$. Creo, finalmente, que los sistemas jurídicos de nuestro entorno pueden satisfacer estas exigencias; son sistemas complejos que combinan distintos tipos de normas, en particular reglas y principios; las reglas pueden contradecirse, pero el sistema cuenta con un acervo de principios y de valores ético-políticos dentro de los cuales puede hallarse una respuesta para cada problema, y que, por tanto, puede disolver objetivamente cualquier caso de antinomia ${ }^{47}$.

3.2. La segunda crítica comprometía el holismo con la tesis del cambio radical, cuyo enunciado resumíamos en la imposibilidad de efectuar el más mínimo cambio entre los elementos del sistema sin modificar por ello la identidad del mismo. La crítica añade que la tesis del cambio radical es incompatible con nuestros sistemas jurídicos, sistemas dinámicos diseñados para experimentar cambios más o menos profundos sin alterar por ello su identidad.

${ }^{44}$ La complejidad de los sistemas como exigencia derivada de la necesidad de resolver sus conflictos es subrayada, por ejemplo, por DeMARCo para la ética (DeMARCO, 1994: 40) y por MARMOR en Derecho (MARMOR, 1991: 405). Complejidad es mayor posibilidad de escrutinio, como muestra que es mejor jurado el que más miembros tiene (OlSSON, 2002: 269-271). Ver también BONJOUR, 1969: 3.

${ }^{45}$ En la imagen de FolEY, una norma inválida es, sin duda, la manzana podrida del cesto (ver nota 20). La idea que defiendo es que la manzana podrida no arruina el cesto si sabemos que no hay más casos en número importante, que alguien tiene la misión de apartarla del cesto en el plazo más breve posible, y que éste cuenta con instrumentos para poder cumplir su tarea.

${ }^{46}$ Creo que el argumento aquí presentado coincide en lo esencial con el de J. Aguiló, para quien «el postulado de la unidad del Derecho, concretado ahora en la idea de unidad práctica, no excluye que puedan darse casos de indeterminación... Lo que sí exige el postulado de la unidad es que estos casos pueden y deben ser resueltos» (AGUILÓ, 2000: 151).

${ }_{47}$ «La unidad sistémica debe ser lo suficientemente vasta como para acoger el dominio de los hechos reales: debe exhibir una cierta compleción» (RESCHER, 1973: 44). El problema de las antinomias remite al problema de la compleción del sistema, y a la inclusión por éste de una respuesta correcta. He relacionado antinomias y holismo sistémico en su versión coherentista en Pérez BERMEJO, 2006: 206-213. Por último, el segundo teorema de GÖDEL («ningún sistema puede probar su propia consistencia») no priva de sentido estas respuestas. Sin que ahora sea posible comentario alguno, me limitaré a sumarme a quienes recuerdan que este teorema sólo es válido para un tipo de sistema formal determinado (dotado de lenguaje formal, axiomas y reglas de inferencia explícitas para demostrar teoremas), y no para otros ámbitos. Ver, por ejemplo, FrAnZÉn, 2005: 7 y 50 . Otras vías de elusión del teorema en, por ejemplo, HALBACH, 2003: 83 y ss. 
Esta crítica no parece haber perturbado excesivamente a las teorías holistas. Éstas han concebido sus sistemas como sistemas no sólo cambiantes, sino proclives al cambio, lo que han subrayado adjudicando al sistema propiedades como la movilidad o la flexibilidad; y si el sistema es móvil, flexible o dinámico es porque está diseñado para modificar su composición interna sin alterar por ello su identidad ${ }^{48}$. Si las teorías holistas se han despreocupado de la crítica del cambio radical es porque la han considerado inocua y fácil de desmontar.

Para responder a esta crítica es preciso distinguir entre cuestiones de justificación y cuestiones de identidad. Las teorías holistas proponen una tesis sobre la justificación de nuestros razonamientos o argumentaciones, pero no incorporan una tesis sobre la identidad de los sistemas. Es cierto que el test holista de justificación vincula ésta con un punto de vista integral relativo a un sistema, porque aprueba como correctas aquéllas conclusiones que se adecuen en mayor medida al sistema en su conjunto. Sin embargo, esta tesis no incorpora un test sobre la identidad del sistema, y menos una tesis que vincule la identidad del sistema con una determinada composición, con una lista precisa de elementos y de relaciones entre los mismos. En realidad, el resultado de aplicar un test holista de justificación puede ser una corrección o una reforma de la composición pretérita del sistema. Cuando el holismo nos exige considerar el sistema en su conjunto o adoptar la perspectiva del todo, lo que sugiere es que, al finalizar el razonamiento o el análisis del problema, nuestras conclusiones deben permitirnos contemplar el sistema como una unidad consistente y cohesionada, y no que debamos tomar la composición pretérita del sistema como un dogma o un axioma inmodificable. Supongamos, por ejemplo, un razonamiento que se debate entre dos conclusiones, $c 1$ y $c 2$. La conclusión $c 1$ es consistente con los elementos del sistema, no introduce contradicción alguna con ninguno de ellos, pero sus conexiones con dichos elementos son muy débiles y escasas. La conclusión $c 2$ mantiene relaciones fuertes y numerosas con muchos elementos del sistema, si bien es inconsistente con un solo elemento del sistema, $x$. Sería un error suponer que el punto de vista del todo o del sistema en su conjunto nos exige justificar $c 1$; la unidad del sistema sale reforzada si insertamos $c 2$ y expulsamos $x$. La perspectiva holista coincide en juzgar esta maniobra como un reforzamiento de las posibilidades de justificación del sistema, y no como un cambio o mutación de sistemas.

Ahora bien, si la identidad no está ligada a la composición exacta del sistema en un momento dado, ¿de qué depende ésta? Es cierto que el sistema puede preservar su identidad a través de los cambios, cambios que pueden llegar a ser extensos y profundos. Sin embargo, esta flexibilidad debe encontrar un límite en algún punto neurálgico del sistema cuyo cambio o supresión implique ya una identidad nueva. Por desgracia, este ensayo no es el lugar idóneo para abordar estos interrogantes en toda su complejidad ${ }^{49}$.

${ }^{48}$ DwOrKIn, 1986: 69-70. Definir el sistema jurídico como un sistema móvil es idea de W. WILbuRg. Presumo aquí que la corriente alemana de teoría jurídica y constitucional denominada «jurisprudencia valorativa» o «jurisprudencia de valoraciones» incorpora un planteamiento holista. Sin espacio para demostrarlo, me remito a LARENZ, 1960: 151.

49 Me ocupo brevemente de este tema en Pérez Bermejo, 2006: 247-253. De modo muy simple, y algo vago, sí puede insinuarse una respuesta especialmente adecuada para las teorías coherentistas. Estas teorías no contemplan el sistema como una estructura de inferencias dotada de una ordenación específica, sino como un todo material aglutinado a partir del sentido de una serie de valores. Esta idea supone que el sistema es compatible con cambios que pueden llegar a ser profundos, pero que no alteran su identidad mientras no se modifique su núcleo de valores básicos. 
En su lugar, resultará más oportuno recapitular la respuesta al problema planteado. El holismo es una teoría sobre la justificación. Es cierto que su punto de vista condiciona la justificación de un elemento a su admisión por un sistema, y eso nos exige resolver el problema desde la perspectiva de la unidad o de la integridad del sistema en su conjunto. Sin embargo, esta respuesta no incluye un test relativo a la identidad y al cambio de los sistemas; tampoco vincula la identidad de los sistemas con una composición concreta de sus elementos, y permite revisiones más o menos profundas de sus contenidos y relaciones.

3.3. La tercera crítica expresaba escepticismo en torno a la necesidad de presumir que el todo actúe integralmente en cada empresa de justificación. Sostuvimos anteriormente que la presunción del todo era la única forma de solucionar lógicamente el problema clásico de la justificación. Sin embargo, la crítica no se siente impresionada por este argumento, y apela a la tozudez de los hechos: los razonamientos jurídicos que habitualmente juzgamos correctos no movilizan el sistema como un todo, sino segmentos que pueden llegar a ser muy reducidos.

Creo que la respuesta a este tipo de objeciones puede inspirarse en el debate sostenido por DwORKIN a propósito del problema de los casos difíciles. DwORKIN ha sido acusado no pocas veces de sobrevalorar los casos difíciles y de subestimar los casos fáciles. Para sus críticos, los casos fáciles son los más frecuentes y representativos de la práctica jurídica, y presentan la característica de obtener una justificación suficiente y completa mencionando una o unas pocas premisas tomadas del Derecho positivo. Ahora bien, creo que estos críticos pasan por alto la distinción entre la estructura superficial de la justificación y la estructura profunda; o, dicho de otro modo, entre la justificación mencionada y la realmente operativa ${ }^{50}$. En los casos fáciles, el juez menciona una parte ínfima del sistema; sin embargo, el sistema como un todo es parte operativa de la justificación completa. De otro modo ni siquiera podríamos explicar por qué dicho caso es un caso fácil: el caso es fácil porque se presume que el resto de los elementos del sistema, especialmente los principios y valores más importantes, están en equilibrio en relación con el caso y, por el momento, no necesitan revisión. La justificación de los casos fáciles presupone, por tanto, una interpretación implícita de todo el sistema, aunque el carácter no problemático de la mayor parte del mismo haga innecesaria su mención ${ }^{51}$. Los casos difíciles, sin embargo, desvelan una superficie mucho más amplia del entramado del sistema: por eso son más instructivos e importantes para el conocimiento del mismo.

Por supuesto, el holismo no implica la consecuencia absurda de que, por ejemplo, el contenido material de todas las normas del Derecho urbanístico sea necesario para la inteligencia de un pequeño discurso de Derecho registral. Sí implica que cada razo-

${ }^{50}$ Que podemos distinguir entre una justificación mencionada y otra operativa está probado por el hecho de que, en algunos ordenamientos, la justificación mencionada es tan incompleta que apenas merece ser comprendida como una verdadera justificación. Éste es el caso del Derecho francés. Las sentencias judiciales en Francia «tienden a ser extremadamente breves y abstractas, abarcando en esencia no más que unas pocas líneas, o bien uno o dos párrafos» (SUMMERS y TARUFFO, 1991: 498). Sin embargo, ello no quiere decir que la labor de los jueces franceses no sea una labor de justificación o razonamiento, sino que la tarea de justificación permanece elidida en una extensa medida, y no se hace explícita en toda su complejidad. Ver la discusión al respecto en SUMMERS y TARUFFO, 1991: 498-500.

${ }^{51}$ DwORKIN, 1986: 354. 
namiento jurídico presupone un juicio de equilibrio sobre la totalidad del sistema jurídico, incluido el Derecho urbanístico. Este juicio de equilibrio significa esencialmente que, cuando el juez examina un caso y le proporciona una respuesta dentro de un determinado sector del sistema, en ningún otro lugar del sistema jurídico se atribuyen respuestas diferentes a casos idénticos o que guarden con éste similitudes relevantes. De haber tratamientos diferenciados en otras ramas del sistema, el juez, sin duda, habrá de extender su discurso y profundizar en el sistema hasta identificar claramente cuál es la voz con la que éste habla, porque está en juego el principio de tratar del mismo modo los casos iguales. Creo que puede aceptarse que ésta es una precaución exigible en cada razonamiento judicial. Esta presuposición de equilibrio o de consistencia en todos los sectores del sistema constituye, por tanto, una exigencia inherente a la práctica jurídica y fundada en los principios básicos de equidad y trato igual. La tesis de la presuposición de todo el sistema en cada razonamiento jurídico no es sólo una tesis lógica, sino también una tesis normativa; por esta causa, las objeciones basadas en argumentos empíricos, relativos a la mayor o menor frecuencia estadística de los casos difíciles, se desvían del núcleo de la discusión, que reside en las consecuencias necesarias derivadas de la equidad y el trato igual.

Por último, es verdad que el holismo supone un cuestionamiento de las fronteras canónicas entre departamentos o ramas del sistema jurídico. Pero, lejos de representar un punto débil, creo que ahí reside una de las virtudes de la teoría. En la práctica jurídica son frecuentes los casos explícitamente transversales, o que integran en las premisas mencionadas normas pertenecientes a una pluralidad de ramas o de departamentos del sistema jurídico; ello es bastante lógico desde que buena parte de los principios o de los valores del sistema informan la totalidad del sistema o muy amplios sectores del mismo. Pero los casos aparentemente fáciles, interpretados con rigor, son también casos transversales, casos en los que, una vez más, el juez realiza una interpretación subyacente sobre el estado de todo el sistema ${ }^{52}$. No debe dejar de observarse que la separación de funciones entre las distintas ramas del sistema jurídico es una convención útil, producto de una tradición que ha sentado importantes precedentes; y si la separación entre ramas o departamentos sienta cierto precedente en nuestras prácticas, entonces hay razones de equidad o de trato igual de los mismos casos para observar los principios propios y distintivos de cada departamento. Sin embargo, esta misma explicación de la importancia de los departamentos descansa en una interpretación del sistema como un todo: si apelamos a la equidad o al trato igual, apelamos entonces a valores y principios morales que están en la base de todo el ordenamiento, y no de un área o departamento. Del mismo modo, si en algún momento puede mostrarse que el conjunto de principios y valores subyacentes al sistema se obedece de mejor forma ignorando esta autonomía y desplazando los principios propios de cada rama, en ese caso el juez puede y debe franquear las fronteras propias de cada departamento.

En suma, el sistema jurídico es algo más que la suma de sus ramas o departamentos, así como de los micro-sistemas o sub-sistemas mencionados por los juristas para

52 En la terminología de BRINK o de BONJOUR, ceñirse a los criterios de cada rama o departamento invoca una interpretación «contextual». Pero, como ambos subrayan, la interpretación contextual presupone siempre una interpretación global. Por ejemplo, nuestro sistema de creencias visuales remite necesariamente a metacreencias sobre el papel del conocimiento empírico, y a teorías que las respalden (BRINK, 1989: 123 y 124; BONJOUR, 1985: 266). 
justificar sus conclusiones: es una unidad, y la justificación jurídica tiene por misión dar cuenta de esta unidad imputando sus conclusiones al sistema en su conjunto.

3.4. Si apelar a la unidad del sistema jurídico puede, tal vez, poseer alguna fuerza intuitiva para algunos juristas, extender dicha unidad al sistema completo de creencias o a la totalidad de nuestras ciencias y saberes merecerá, probablemente, un mayor escepticismo.

Hay que advertir que, como revela una mirada más atenta a las teorías holistas, la tesis de la unidad del conocimiento no es una tesis postulada de forma unánime por sus cultivadores. No son pocos quienes postulan la unidad o la integridad de su particular rama de conocimientos, pero no presumen una tesis semejante para todas las demás ${ }^{53}$. Sin embargo, pese a no ser una tesis unánime, no debe dejar de subrayarse que es una tesis mayoritaria, y que las razones en su favor son de bastante peso a tenor de lo dicho en el epígrafe 2.

Creo que las alegaciones contra esta crítica deben empezar admitiendo, como cuestión meramente fáctica, la división del trabajo científico en una serie de prácticas autónomas dotadas de valoraciones y de fines propios. Como ya expresaba BRADLEY, «la vida en general y el conocimiento en particular dependen de la distinción y la división de regiones separadas. Aunque estas regiones divididas no sean independientes unas de otras, ni tampoco auto-suficientes, en gran medida hemos de proceder como si lo fueran $»^{54}$. La autonomía relativa de estas prácticas o dominios del saber queda refrendada en juicios o en actitudes que emitimos en el lenguaje ordinario. Así, por ejemplo, hallamos sentido a la frase: «no importa que $\mathrm{X}$ fuese nazi: fue un gran cineasta», de modo que una valoración muy negativa en el ámbito de la política o la moral no perjudica una valoración muy positiva en el dominio del arte. Por las mismas razones, entendemos que la frase «¿cómo puede ser bueno un cuadro en el que se representa un unicornio, cuando los unicornios no existen?» descansa en una confusión radical entre prácticas muy distintas y regidas por criterios de valoración independientes. Fiel a esta división del trabajo, el Derecho se reclamaría entonces como un dominio diferenciable de otros como la moral, el arte o las ciencias naturales. Su autonomía relativa se revela en su obediencia a fines y valoraciones propios. Significativamente, estas valoraciones no son coincidentes con las que presiden el dominio de la moral; incluso quienes sostienen la tesis de la unidad del razonamiento práctico no dejan de subrayar igualmente que el razonamiento jurídico es un razonamiento diferenciable del razonamiento moral, y distinguido por el importante papel que desempeña la autoridad, por su carácter «regimentado»o, en suma, por su carácter institucional ${ }^{55}$. El mismo DWORKIN, al tiempo que acentúa el carácter imparable e ilimitado de la expansión holista, tampoco deja de reconocer la existencia dentro del sistema jurídico de fuerzas centrípetas que la limitan: en el marco de la práctica jurisdiccional, los valores de la equidad y del procedimiento debido abogan por una integridad «inclusiva» que nos llama a respetar las decisiones y las prácticas jurídicas del pasado, y que nos disuade de subvertirlas apelando a razones de justicia independientes ${ }^{56}$.

\footnotetext{
53 Duhem, 1906: comienzo del capítulo VI; Moulines, 1986: 319 y ss.

54 BRADLEY, 1914: 266.

${ }^{55}$ Me remito aquí a ideas muy conocidas de Nino, Alexy, AtienZa o Ruiz Manero.

${ }^{56}$ DwORKIN, 1986: 404-6.
} 
Ahora bien, creo que las dos frases anteriores también expresan que la separación entre prácticas es relativa y limitada. Formularé en primer lugar la tesis que defiendo, y trataré de explicarla después volviendo sobre estos dos casos. Esta tesis puede exponerse a partir del anterior texto de Bradley. El texto señalaba que, en efecto, actuamos dentro de cada práctica o dominio científico «como si» éstos fuesen independientes unos de otros; sin embargo, también sabemos que no lo son del todo. ¿En qué medida el practicante de un dominio científico puede saber o puede presumir que su ámbito no es del todo independiente? ¿Qué presunción puede abrigar un jurista respecto a la totalidad del saber? Creo que, necesariamente, el jurista opera mediante una presunción relativa a todo el mapa del saber; con esta imagen me refiero a un conocimiento relativo a los distintos conceptos con los cuales elaboramos las fronteras entre disciplinas. Cuando menos, el jurista posee una idea operativa de la influencia que sobre su propia práctica ejercen las conclusiones extraídas en la moral o en las ciencias naturales. Así, por ejemplo, una tesis sobre la eutanasia ampliamente defendida por la moral o una tesis sobre el concepto de muerte clínica ampliamente aceptada por la neurología interrogan directamente su labor, y el jurista ha de concluir en qué medida el sistema jurídico está o no influido, condicionado, determinado o es del todo indiferente a lo que pueda ser aseverado en estos dominios. En suma, el jurista presupone una conceptualización de todas las ramas del saber suficiente para trazar las fronteras entre las distintas ramas del conocimiento en relación con el Derecho. Para elaborar esta idea, el jurista se sirve de una teoría o una concepción relativa a los límites de la práctica jurídica, la moral, las ciencias, y otros dominios que puedan entrar en colisión con el suyo, así hasta componer un mapa completo de las distintas ramas del saber ${ }^{57}$. Esta teoría tratará de acomodar todos los fines y criterios de valoración propios de las distintas prácticas dentro de un esquema ordenado y coherente, de modo que todos ellos presenten un estado de equilibrio. Dado que es el jurista quien lleva a cabo esta tarea de conceptualización, y dado que la lleva a cabo en el contexto de su práctica específica, la teoría será una teoría interna al Derecho o propiamente jurídica. Su consecuencia, sin embargo, es de alcance global, porque consiste en un esquema de conceptos en el que estén acomodados todos los campos del saber. Por último, esta teoría o conceptualización global será revisable, porque la dificultad de ciertos casos nos interrogará en torno a la coherencia del esquema global defendido. Creo que la tesis, así presentada, es compatible con la percepción ordinaria de quienes practican las distintas ramas del saber, y que distinguen su práctica como una práctica autónoma y dotada de valoraciones propias; en el caso de la práctica jurídica, la idea es conciliable con la del jurista práctico y especializado, que puede percibir en su práctica una independencia de facto. Al mismo tiempo, la idea hace realista y verosímil la vieja fórmula holista según la cual el razonamiento propio de una determinada práctica, como la práctica jurídica, no puede comprenderse sin implicar un punto de vista sobre el saber en general ${ }^{58}$.

${ }^{57}$ Lo que a continuación afirma MouLINES sobre los perfiles de una posible teoría es también aplicable a los perfiles de un dominio del saber, por ejemplo el Derecho: «El proceso de identificación de una teoría... también muestra rasgos holistas. Usted no puede determinar dónde se halla el ámbito de aplicación de la teoría tomando la teoría aisladamente: necesita considerar varios tipos de relaciones entre esta teoría y otras teorías». MOULINES, 1986: 327

${ }^{58}$ Creo que este punto de vista se adecua a las opiniones de V. VILLA, que apuesta por combinar la imagen unitaria de la ciencia y la autonomía metodológica parcial de cada una de las ciencias particulares. No creo que sea necesario apelar a una tradición filosófica post-positivista y wittgensteiniana para defenderla, como sí 
Volviendo a las dos frases anteriores, creo que el juicio «el cineasta $\mathrm{X}$ era un artista excelente pese a su filiación nazi» incorpora algo más que una mera descripción de la práctica artística contemporánea, o la aplicación analítica de una definición de arte que podamos hallar en un diccionario: incorpora una teoría que sirve para conceptualizar las relaciones entre el arte y los otros dominios del saber (como la política), y para la cual el concepto de arte se halla despojado de compromisos morales, sociales y políticos. Pese a que estas conceptualizaciones obtienen frecuentemente un grado de consenso muy elevado, existen casos extremos que ponen en cuestión la teoría de la que proceden. De ese modo, la acusación de «dogmatismo del todo» con la que concluíamos el epígrafe 2 no tiene sentido: la teoría que sirve para vertebrar el todo es cuestionada de modo explícito en casos limítrofes que nos obligan a revisarla y a replantearnos su justificación. De hecho, la frase de nuestro ejemplo representa uno de estos casos difíciles, porque ha inducido con frecuencia a invocar teorías alternativas; se ha alegado así, por ejemplo, que el arte está ligado a funciones de liberación social, lo que podría justificar una conclusión como «el cine de $\mathrm{X}$ no es arte, sino demagogia». En cualquier caso, tanto este juicio como el anterior son juicios puramente internos a la práctica artística, y se justifican mediante teorías genuinamente estéticas: no son juicios políticos o morales, ni tampoco una mezcla confusa de arte y de política. Sin embargo, incorporan al mismo tiempo una conceptualización precisa entre los dominios del arte, de la política y de todos los demás. Es posible así compatibilizar una visión omnicomprensiva de las distintas ramas del saber y la percepción autónoma de cada práctica. Del mismo modo, el juicio «no aplicaré esta ley porque es extremadamente injusta» sería también un juicio genuinamente jurídico y justificado mediante argumentos internos al sistema; se podrá estar de acuerdo o no con la teoría o concepción de la práctica jurídica que subyace a dicho juicio, pero no discutir su carácter propiamente jurídico. $\mathrm{Y}$, al mismo tiempo, el juicio presume una teoría sobre las relaciones entre Derecho, justicia y grados de injusticia, lo que remite a una teoría compleja de las relaciones entre Derecho y moral.

Por otro lado, en el caso del cuadro del unicornio, si juzgamos fuera de contexto la opinión de nuestro biólogo es también porque defendemos una concepción particular del arte en la que liberamos a éste de un compromiso necesario con la realidad empíricamente perceptible. El ejemplo nos sirve para salir al paso de un posible malentendido. Presumir que existen prácticas autónomas y dotadas de valoraciones propias, como hemos presumido nosotros, no implica una disolución contextualista de los conceptos de razón, objetividad y verdad en tantas versiones como prácticas distingamos. Al contrario, la tesis que propugnamos es que ha de existir un esquema coherente e in-

declara VILLA. Por otra parte, creo que la tesis aquí defendida se adecua a los anhelos de Harman de un holismo menos extremo que el representado por la integración de todo nuestro saber dentro de un sistema compacto, obediente a baremos unificados e invocado siempre en su totalidad. Podemos estar de acuerdo con HARMAN en que esta última tesis incorpora una idealización excesiva. Ver HARMAN, 1989: 112. El hecho de que la conceptualización de las distintas prácticas tenga lugar desde la perspectiva de la práctica jurídica nos libera de la presunción, realmente problemática, de que cada razonamiento jurídico supone la movilización de todo nuestro saber: no presumimos todo nuestro saber materialmente considerado, sino sólo una conceptualización de sus distintas ramas, una especie de mapa de situación relativo a sus límites y fronteras. De ese modo, el problema de cómo presumir el acceso cognitivo a la totalidad de nuestro conocimiento, que condujo a muchos teóricos holistas del conocimiento a proponer expedientes y recursos muy discutibles, queda desactivado en buena medida. Ver, por ejemplo, los problemas del expediente de BONJOUR, el recurso a la llamada «presunción doxástica», en BONJOUR, 1985: 103-106. 
cluso de apoyo mutuo entre los distintos fines y valoraciones que presiden cada práctica autónoma $\mathrm{a}^{59}$. La réplica que le dirigimos al biólogo no incluye necesariamente juicios como «en arte hacemos real lo que en ciencia es irreal», «los conceptos de verdad y de objetividad en arte son completamente distintos a los de las ciencias», o «en arte los unicornios sí son reales»; nuestra postura se limita a defender una concepción del arte que permite calificar el cuadro debatido como una manifestación artística, y, probablemente, consideraría los anteriores juicios como exagerados e innecesarios. Del mismo modo, definir una conceptualización general de las distintas prácticas y su influencia en el Derecho a partir o desde la perspectiva de la práctica jurídica no implica una reconstrucción local y particular de las ideas de verdad, objetividad y realidad que se formule con absoluta independencia de las que rigen en las ciencias naturales; al contrario, los conceptos de verdad o de realidad que se introduzcan en la práctica jurídica habrán de conciliarse con los que están vigentes en otras prácticas, de modo que, si bien puede haber ocasiones en las que puedan divergir, no pueden aislarse de los mismos. Creo que esta idea se halla reflejada en el conocido expediente de la ficción jurídica. Nuestro Tribunal Constitucional define la ficción como un instrumento por el que, «contrariando la realidad», se introduce en el ámbito de aplicación de la norma un supuesto de hecho que, de otro modo, estaría excluido del mismo ${ }^{60}$. Las razones por las cuales admitimos este tipo de afirmaciones son razones internas, necesidades de equidad o de justicia que se nos antojan especialmente importantes, y que nos llevan incluso a clasificar un caso dentro de un género al que no pertenece desde los tests epistémicos más frecuentes ${ }^{61}$. Ahora bien, aun en la hipótesis de que tolerásemos tanto el recurso como la definición del mismo que nos proporciona el Constitucional ${ }^{62}$, creo que resultará pacífico afirmar que la ficción no puede servir para proclamar sinsentidos o enunciados absurdos, o para negar hechos probados por las fuentes históricas, y ello aun cuando concurran argumentos de equidad y de justicia de cierto peso o importancia ${ }^{63}$.

59 Ésta es la única forma de evitar que ciertos ámbitos internamente coherentes, como la astrología y otros, se erijan en ámbitos auto-justificados merced a sus particulares baremos de verdad, objetividad y realidad. Ver THAGARD, 2004: sección «Isolation».

${ }_{60}$ STC 165/94 de 26 de mayo, fundamento jurídico 5. Creo que definición se asemeja a una de las definiciones doctrinales más conocidas: la de Lon FuLLER. Como es sabido, este autor no duda en definir la ficción jurídica como enunciado falso (FULLER, 1930-31: 9), con las eximentes de que los jueces son plenamente conscientes de su falsedad y no abrigan la intención de engañar a nadie.

${ }^{61}$ De hecho, si estas razones internas no se justifican, no será admisible incluir el caso en el supuesto de hecho al que no pertenece. No se puede, por ejemplo, invocar el instrumento de la ficción para violar la letra de leyes tan importantes como la Constitución. Para estos casos, el TC habla en el mismo párrafo de «imposibilidad jurídica». Sobre la inconveniencia de las ficciones en el Derecho constitucional, véase CALABRESI, 1985: 87-117.

${ }^{62}$ No enfrentaremos esta interpretación con otras como la de GRAY, para quien una ficción es un mandato (GRAY, 1921: 32), o como la de HERNÁNDEZ MARÍN, para quien una ficción jurídica es un enunciado cualificatorio (1986: 141). El problema se complica aún más si distinguimos entre tipos de ficciones. Hay ficciones lógicas, en las cuales la afirmación falsa no es más que una herramienta lógica provisional que luego se desecha como mero andamiaje intelectual una vez demostrada la tesis defendida; hay ficciones narrativas y metafóricas, en las cuales la afirmación no sólo no se desecha, sino que se convierte en una especie de verdad jurídica... Definir el recurso de la ficción debería ser sensible a estas diferencias, lo que no siempre sucede. Ver Notes, 2002: 2228-2249.

${ }^{63}$ Como concluye CAmPBelL, alterar el ámbito de aplicación de la regla debe ser contrapesado con la pérdida de credibilidad que está implícita en cualquier alejamiento de nuestras concepciones normales sobre la realidad. Éste es, precisamente, el aspecto sobre el que BENTHAM concentró su famoso ataque a esta figura. CAMPBELL: 1983, 370. Ejemplo bien conocido de ficción que proclama un sinsentido es la decisión del juez británico 
En suma, la suposición del sistema como totalidad incorpora una conceptualización de los límites del sistema jurídico, así como de los límites de otros sistemas de normas y de creencias, y ello porque todos estos sistemas son fuente permanente de casos difíciles que interrogan y ponen en cuestión las fronteras del sistema jurídico. El jurista necesita una teoría relativa al mapa completo del saber en relación con el sistema jurídico. Así interpretada, esta tesis puede neutralizar las críticas frecuentemente vertidas contra las visiones omnicomprensivas del saber: en primer lugar, esta tesis es compatible con la autonomía de la práctica jurídica; en segundo lugar, lo que esta tesis demanda del jurista no es más que una teoría jurídica, una concepción del Derecho y en relación con el Derecho que dé respuesta a interrogantes frecuentemente dirigidos a su práctica ${ }^{64}$.

\section{BIBLIOGRAFÍA}

Aguiló, J., 2000: Teoría general de las fuentes del Derecho (y del orden jurídico), Barcelona: Ariel. AlBERT, H., 1968: Traktat über kritische Vernunft, Tübingen: Verlag Mohr.

Alchourrón, C., y Bulygin, E., 1971: Normative Systems, New York: Reidel. Cito por la traducción al castellano de los autores: Introducción a la metodología de las ciencias jurídicas y sociales, Buenos Aires: Astrea, 1993.

BAR-YAR, Y., 2003: Dynamic of Complex Systems, New York: Perseus Book Group.

Baum Levenbook, B., 1984: «The Role of Coherence in Legal Reasoning», Law and Philosophy, 3 .

BONJOUR, L., 1969: «Knowledge, Justification and Truth», disertación presentada en Princeton University. En http://www.ditext.com/bonjour/bonjour. Última consulta: 30-VI-2007.

- 1985: The Structure of Empirical Knowledge, Cambridge: The Cambridge University Press.

- 2003: «In Search of Coherentism». En BONJOUR, L., y SOSA, E.: Epistemic Justification, Malden: Blackwell Publishing.

Bradley, F. H., 1914: Essays on Truth and Reality, Oxford: The Clarendon Press.

BRINK, D. O., 1989: Moral Realism and the Foundations of Ethics, Cambridge: The Cambridge University Press.

Brown, C., 2007: «Two Kinds of Holism about Values», The Philosophical Quaterly, 57.

Bunge, M., 1999: Buscar la filosofía en las ciencias sociales, Madrid: Siglo XXI Editores.

Calabresi, G.: Ideals, Beliefs, Attitudes and the Law: Private Law Perspectives on a Public Law Problem, Syracuse (New York): The Syracuse University Press.

CAmpBell, K., 1983: «Fuller on Legal Fictions», Law and Philosophy, 2.

Costanzo, A., 1992: Condizione di incoerenza, Milano: Giuffrè.

que situó la isla de Menorca no en el Mediterráneo, sino en la parroquia de St. Mary Le Bow de Londres. Es muy cierto que esta aserción no podía ni quería engañar a nadie sobre la geografía de la isla; es dudoso, sin embargo, que ello redima por sí solo el razonamiento del juez (GRAY, 1921: 34). Ejemplo de manipulación histórica innecesaria es el voto particular del juez Marshall en City of Richmond v. J.A. Croson Co., que recordaba la «larga tradición de trato especialmente sensible a los problemas raciales» del Derecho americano. Notes, 2002: 2239.

${ }^{64}$ Este trabajo se inscribe en el marco del proyecto de investigación «Interpretación, argumentación y sistema jurídico» (Referencia SEJ2007-63792), beneficiado con una ayuda por la Dirección General de Investigación. Tampoco hubiera sido posible sin las observaciones y sugerencias del Prof. Miguel Ángel Rodilla, al que debo lo que pueda haber de bueno en este artículo. 
DAVIDSON, D., 1984: Inquiries into Truth and Interpretation, Oxford: The Clarendon Press.

Demarco, J. B., 1994: A Coberence Theory in Ethics, Amsterdam: Rodop.

DuHem, P., 1906: La théorie physique; son object; sa estructure. Cito por la versión inglesa «Physical Theory and Experiment», New Readings in the Philosophy of Science, New York: 1951.

DwOrKIn, R., 1986: Law's Empire, Cambridge: The Harvard University Press, 1986.

- 1991: Foundations of Liberal Equality, Salt Lake City: University of Utah Press. Cito por su edición en S. DARWALL y A. ARBOR (eds): Equal Freedom: Selected Tunner Lectures on Human Values, The University of Michigan Press, 1995.

— 1996: «Objectivity and Truth: You'd Better Believe It», Philosopby and Public Affaires, 25. Cito por wwwserver.nyu.edu. Última consulta: 30-VI-2007.

EDmundSON, W., 1994: «Comments on "The Coherence Theory in the Philosophy of Law"». En http://law.gsu.edu/wedmundson/COHERENT.TLK.pdf. Última consulta: 30-VI-2007.

FODOR, J., y LEPORE, E., 1992: Holism. A Shopper Guide, Oxford: Basil Blackwell.

FOLEY, R., 1979: «Justified Inconsistent Beliefs», American Philosophical Quaterly, 16.

FrANZÉN, T., 2005: Gödel's Theorem: An Incomplete Guide to Its Use and Abuse. Massachusetts: AKPeters.

FUlLER, L., 1930-31: «Legal Fictions», Illinois Law Review, 25. Cito por la reedición de 1967 de Stanford, California: Stanford University Press.

Goldman, A., 1989: «Bonjour's Structure of Empirical Knowledge». En J. W. BendER (ed.), The Current State of Coherence Theory, Dordrecht: Kluwer Academie Publishers.

GRAY, J. C., 1921: The Nature and Sources of Law, Gloucester: Peter Smith, reimp. 1972.

Guastini, R., 1996: Distinguendo. Studi di teoria e metateoria del diritto, Torino: Giappichelli. Cito por la traducción al castellano de J. FERRER: Distinguiendo. Estudios de teoría y metateoría del Derecho, Barcelona: Gedisa, 1999.

— 2004, «Proyecto para la voz "ordenamiento jurídico" de un diccionario», Doxa, 27.

HAACK, S., 1993: Evidence and Inquiry, Oxford: Blackwell. Cito por la traducción de M. A. MARTíNEZ, Evidencia e investigación, Madrid: Tecnos, 1997.

HalbaCh, V., 2003: «Can We Grasp Consistency?». En E. J. Olsson (ed.), The Epistemology of K. Lebrer, Dordrecht: Kluwer Academic Publishing.

Harman, G., 1973: Thought, Princeton: The Princeton University Press.

- 1989: Change in View, Cambridge: MIT Press.

HERNÁNDEZ GIL, A., 1979: «La noción de sistema en Savigny». En Savigny y la ciencia del Derecho, I, Revista de ciencias sociales. Valparaíso: Facultad de Ciencias Jurídicas, Económicas y Sociales.

HERNÁNDEZ MARÍN, R., 1986: «Ficciones jurídicas», Doxa, 3.

Hoffmaster, B., 1980: «A Holistic Approach to Judicial Justification», Erkenntnis, 15.

JoACHIM, H., 1977: The Nature of Truth, Westwood: Greenwood Press.

LARENZ, K., 1960: Methodenlebre der Rechtswissenschaft, Berlin, Springer: Cito por la traducción de M. Rodríguez Molinero: Metodología de la ciencia del Derecho, Barcelona: Ariel, 2001.

LEHRER, K., 1997: Self-trut. A Study of Reasons, Knowledge and Autonomy, Oxford: The Clarendon Press.

- 1999: «Justification, Coherence and Knowledge», Erkenntnis, 50.

MacCormick, N., 1984: «Coherence in Legal Justification». En A. PeCZENIK, et al. (eds.), Theory of Legal Science, Dordrecht: Reidel Publishing.

- 1993: «Argumentation and Interpretation in Law», Ratio Iuris, 6. 
MARMOR, A., 1991: «Coherence, Holism, and Interpretation: The Epistemic Foundations of Dworkin's Legal Theory», Law and Philosophy, 10.

MoOre, M., 1989: «The Interpretative Turn in Legal Theory; a Turn for the Worse?», Stanford Law Review, 41.

— 1992: «Moral Reality Revisited», Michigan Law Review, 90.

Moreso, J. J., y NavarRo, P. E., 1993: Orden jurídico y sistema jurídico, Madrid: Centro de Estudios Constitucionales.

Moulines, U., 1986: «The Ways of Holism», Nô̂s, 20.

Notes, 2002: «Lessons from Abroad: Mathematical, Poetic and Literary Fictions in the Law», Harvard Law Review, 115.

OlssON, E. J., 1999: «Cohering with», Erkenntnis, 50.

- 2002: «What is the Problem of Coherence and Truth?», The Journal of Philosopby, 99.

Osborne, G., 1991: The Hermeneutical Spiral, Downers Grove: InterVarsity Press.

Pagin, P., 2005: «Meaning Holism». En E. Lopore y B. SMITH (eds.), Handbook of Philosophy of Language, Oxford: The Oxford University Press.

Peacocke, C., 1999: «Holism». En B. Haley y C. Wright (eds.) A Companion to Philosophy of Language, Malden: Blackwell.

Pérez Bermejo, J. M., 2006: Coberencia y sistema jurídico, Madrid: Marcial Pons.

POLLOCK, J., 1997: «A Plethora of Epistemological Theories». En G. PAPPAS (ed.), Justification and Knowledge, Dordrecht: Reidel Publishing co.

Putnam, H., 1986: «Meaning Holism». En L. E. Hahn y P. A. SchilpP (eds.) The Philosophy of W. V. Quine, Chicago: Open Court, III.

Quine, W. V. O., 1963: From a Logical Point of View, New York: Harper \& Row.

RATTI, G. B., 2006: Sistema giuridico e sistemazione del diritto, Milano: 2006, inédito.

RAZ, J., 1970: The Concept of a Legal System. Oxford: The Clarendon Press.

- 1994: «The Relevance of Coherence», Ethics in the Public Domain, Oxford: The Clarendon Press.

Rescher, N., 1973: The Coherence Theory of Truth, Oxford: The Oxford University Press.

- 1974: «Foundationalism, Coherentism, and the Idea of Cognitive Systematization», The Journal of Philosophy, 71.

Rodríguez, J. L., 2002: Lógica de los sistemas jurídicos, Madrid: Centro de Estudios Políticos y Constitucionales.

RotT, H., 2001: Change, Choice and Inference, Oxford: The Clarendon Press.

SARTORIUS, R., 1968: «The Justification of Juditial Decision», Ethics, 78.

SAVIGNY, F. K. vON, 1849: System des heutige romanischen Recths, I. Berlin: Veit und com. Cito por la traducción al castellano de W. GOLDSCHMIDT, «Los fundamentos de la ciencia jurídica», La ciencia del Derecho, Buenos Aires: Losada, 1949.

SosA, E., 1980: «The Raft and the Pyramid: Coherence versus Foundations in the Theory of Knowledge», Midwest Studies of Philosopby, 5.

SpOHN, W., 1999: «Two Coherence Principles», Erkenntnis, 50.

Stavropoulos, N., 1996: Objectivity in Law, Oxford: The Clarendon Press.

SummerS, R. S., y TARUfFO, M., 1991: «Interpretation and Comparative Analysis», en Robert S. Summers y N. MACCORMicK eds., Interpreting Statutes, Aldershot: Dartmouth.

Tersman, F., 1993: Reflective Equilibrium, Stockholm: Almqvist \& Wiksell International.

THAGARD, P., et al., 2004: «Knowledge and Coherence», http://cogsci.uwaterloo.ca/Articles/Pages/epistemic.html. Última consulta: 30-VI-2007. 
VILLA, V., 1984: «Legal Science between Natural and Human Sciences», Legal Studies, 4. VIOLA, F., 1987: Autoritá e ordine nel diritto, Torino: Giappichelli.

Williams, M., 1991: Unnatural Doubt, Oxford: Blackwell, 1991.

- 1999: Groundless Belief. Second edition, Princeton: The Princeton University Press.

Young, J. O., 1995: Global Anti-realism, Aldershot: Avebury. 